\title{
The Role of the Electrokinetic Charge of Neurotrophis-based Nanocarriers: Protein Distribution, Toxicity and Oxidative Stress in in Vitro Setting
}

\section{Maria Dąbkowska ( $\nabla$ maria.dabkowska@pum.edu.pl)}

Pomeranian Medical University https://orcid.org/0000-0003-0190-1292

\section{Zofia Ulańczyk}

Pomeranian Medical University in Szczecin: Pomorski Uniwersytet Medyczny w Szczecinie

Karolina Łuczkowska

Pomeranian Medical University in Szczecin: Pomorski Uniwersytet Medyczny w Szczecinie

\section{Dorota Rogińska}

Pomeranian Medical University in Szczecin: Pomorski Uniwersytet Medyczny w Szczecinie

\section{Anna Sobuś}

Pomeranian Medical University in Szczecin: Pomorski Uniwersytet Medyczny w Szczecinie

\section{Monika Wasilewska}

Pomeranian Medical University in Szczecin: Pomorski Uniwersytet Medyczny w Szczecinie

\section{Maria Olszewska}

Pomeranian Medical University in Szczecin: Pomorski Uniwersytet Medyczny w Szczecinie

\section{Katarzyna Jakubowska}

Pomeranian Medical University in Szczecin: Pomorski Uniwersytet Medyczny w Szczecinie

\section{Bogusław Machaliński}

Pomeranian Medical University in Szczecin: Pomorski Uniwersytet Medyczny w Szczecinie

\section{Research}

Keywords: Electrokinetic Charge, Nanocarriers, Toxicity, Oxidative Stress

Posted Date: May 5th, 2021

DOl: https://doi.org/10.21203/rs.3.rs-451702/v1

License: (c) (1) This work is licensed under a Creative Commons Attribution 4.0 International License. Read Full License 


\section{Abstract}

\section{Background}

The rational chemical design of nanoparticles can be readily controlled and optimized by quantitatively studying protein adsorption at variously charged polymer carriers, which can determine their fate in biological fluids. We manufactured brain-derived neurotrophic factor (BDNF) -based electrostatic nanocomplexes with different type of dendrimer core (anionic or cationic), encapsulated or not in polyethylene glycol (PEG), and studied their physicochemical properties and behavior in biological setting. We investigated whether the electrokinetic charge of dendrimer core influences BDNF loading and desorption from the nanoparticle and serves as a determinant of nanoparticles' behaviour in in vitro setting, influencing mitochondrial dysfunction, lipid peroxidation and general nanoparticles' cellular toxicity.

Results

We found that elektrokinetic charge of the dendrimer core influences nanoparticles in terms of BDNF release profile from their surfaces and their effect on cell viability, mitochondrial membrane potential, cell phenotype and induction of oxidative stress. The electrostatic interaction of positively charged core of nanoparticles with cell membranes decreases their cytotoxicity, as well as increases serious phenotype alterations in comparison to negatively charged nanoparticles core in neuron-like differentiated human neuroblastoma cell. Moreover, PEG adsorption at nanoparticles with negatively charged core present a distinct decrease in metabolic cell activity. On the contrary, charge neutralization due to PEG adsorption on the surface of nanoparticles with positively charged core does not reduce their cytotoxicity makes them less biocompatible with differentiated cells and presumably show non-specific toxicity.

\section{Conclusions}

The surface charge transformation after adsorption of protein or polyelectrolyte during nanocarriers formulation has an important role not only in designing nanomaterials with potent neuroprotective and neuroregenerative properties but also in applying them in cellular environment.

\section{Background}

Recent nanotechnology advancements have enabled introduction of nanoparticles (NPs) that have potential applications in a variety of areas; in the medicine field they are used as delivery systems for drugs, proteins and DNA ${ }^{1,2}$. To date, NPs have been constructed from various substances including metal and non-metal, polymeric, and bioceramic materials ${ }^{3}$. Liposomes, polyethylene glycol (PEG), and dendrimers are the main constituents of NPs used for therapeutic applications ${ }^{4,5}$. Regardless of their chemical composition, protein-loaded NPs should allow efficient loading and retention of the therapeutic protein, offer high stability in the biological setting, and ensure fast release of protein that is readily available for its receptors at its desired site of action 6,7 . 
It is particularly tempting to utilize protein-loaded NPs in the central nervous system (CNS), as the anatomical obstacle in the form of blood-brain barrier (BBB) makes free protein delivery to the tissue of interest particularly challenging. Neurotrophins, including brain-derived neurotrophic factor (BDNF), have been interesting therapeutic protein candidates for neurodegenerative disorders, particularly for their neuronal survival-promoting features ${ }^{8}$. The utilization of NPs for neurotrophins delivery to the brain tissue could improve their therapeutic potency by increasing circulation time and bioavailability at the targeted site ${ }^{9}$. However, since general NPs limitation in an in vivo setting, which greatly reduces therapeutic effects of transported proteins, is clearance via the mononuclear phagocytic system ${ }^{10}$, neurotrophins-loaded NPs design requires proper understanding of their physicochemical properties that may influence their behaviour in biological milieu.

Polyamidoamine (PAMAM) dendrimers have been considered a promising material for NPs designed for CNS delivery, as they have several beneficial features: high stability and water-solubility, small size, presence of cavities and modifiable surfaces ${ }^{11,12}$. In fact, PAMAM dendrimer attributes (core, size of dendrimer/cavities, functional groups on the surface) can be accurately modified and thus provide a range of NPs for in vitro or in vivo drugs delivery to brain cells ${ }^{13,14}$. Additional PEGylation (PEG modification) of PAMAM surface is simple and effective way to reduce aggregation, phagocytosis and thus improve encapsulation, biocompatibility and targeting of the drug ${ }^{5,15}$. However, the precise mechanism of how (and even if) the dendrimer enters the cell and how the transported protein is released remains not fully understood ${ }^{16}$.

It has been hypothesized that surface charge of the dendrimer is an important factor in considering NPs effectives: it influences cellular uptake, biocompatibility, receptor binding and toxicity, and is also linked with the capacity to produce reactive oxygen species (ROS) ${ }^{17}$. The electrostatic interaction between PAMAM dendrimers with positively charged amino groups and negatively charged cell membrane could lead to significant thinning and disruption of the biological lipid bilayer membrane, including formation of nano-holes ${ }^{18,19}$. It has been suggested that positively-charged NPs show less systemic benefits, as they are more prone to unintended liver uptake, which is generally in concordance with observation that cationic macromolecules are more rapidly cleared from plasma ${ }^{20}$. On the contrary, Florendo et al. hypothesized that positive charge on dendrimers enhances adsorptive endocytosis and enables easier cell membrane crossing ${ }^{13}$. It makes things even more complicated that when desired protein is adsorbed onto NP surface it can generate a change in zeta potential, independent of initial surface charge 5,21 . Since the surface charge affects not only cellular uptake of NPs, but also retention in circulation ${ }^{16,22}$, the precise knowledge on the charge in NPs design is of great importance.

The main goal of our study was to thoroughly characterise PAMAM- and PEGylated PAMAM-based nanoparticles with differently charged PAMAM cores. We investigated whether the electrokinetic charge of PAMAM core in PAMAM-based nanoparticles influences BDNF loading and desorption from the nanoparticle. We also aimed to establish whether PAMAM core charge serves as a determinant of 
nanoparticles' behaviour in in vitro setting, influencing mitochondrial dysfunction, lipid peroxidation and general nanoparticles' cellular toxicity.

\section{Material And Methods}

\section{Preparation and characterization of PAMAM-based nanoparticles with negative/ positive core:}

The suspension of ethylenediamine core five and a half generation dendrimers (PAMAM G5.5) with sodium carboxylate surface groups, (536784, Sigma Aldrich, St. Louis, MO, USA) as well as ethylenediamine core six generation dendrimers (PAMAM G6) with amino surface groups, (536717, Sigma Aldrich) were used as a colloid carrier for BDNF. Each stock suspension was diluted prior to each adsorption experiment to a desired mass concentration, equal to $10 \mathrm{mgL}^{-1}$. Filtered (centrifree ultrafiltration device, Merck Group, Darmstadt, Germany) stock solutions of carrier free recombinant human BDNF (248-BDB-250/CF, R\&D Systems, Canada) of known concentrations (typically $50 \mathrm{mgL}^{-1}$ ) in the phosphate buffered saline (PBS) pH 7.4 +/- 0.2, 0.15M (Biomed, Lublin, Poland) were prepared to remove aggregates and provide constant, free form protein molecules concentration before adsorption at PAMAM particles. To minimize errors in concentration measurements spectrophotometric techniques the BCA (protein quantification bicinchoninic acid assay, kit for low concentration, Abcam, Cambridge, UK) were used. BDNF adsorption at PAMAM dendrimers was performed employing electrostatic interactions according to the following procedure: (1) the reference electrophoretic mobility of bare PAMAM nanoparticles was measured, (2) BDNF layers were formed by mixing equal volumes of its solutions of the $0.2 \mathrm{mgL}^{-1}$ bulk concentration, with nanoparticle suspension of the bulk concentration $20 \mathrm{mgL}^{-1}$, (3) the electrophoretic mobility of BDNF-PAMAM nanoparticles was measured and the corresponding zeta potential was calculated. We obtained BDNF-PAMAM nanoparticles, referred to as "PAMAM-based nanoparticles". Experiments were conducted at $7.4 \mathrm{pH}$, ionic strength $0.15 \mathrm{M}$, at room temperature. The whole experimental procedure was performed for adsorption time of 6000 seconds. Afterward, BDNFPAMAM dendrimer nanoparticles were encapsulated with PEG (poly(ethyleneglycol)) with molecular weight of $4 \mathrm{kDa}$, (1546569, Sigma Aldrich). We carried out simply mixing BDNF-PAMAM and PEG in aqueous solutions without sonification or other extensive agitation. PEG chains were conjugated to the nanoparticle surfaces via amide or carboxyl bonds depending on type of PAMAM core charge, formation between PEG amino groups and PAMAM surface groups. An equal volume of beforehand prepared BDNFPAMAM and PEG (50 $\mathrm{mgL}^{-1}, \mathrm{pH} 7.4$, PBS) solutions was prepared by mixing at room temperature for $1 \mathrm{~h}$. Next, PEG-ylated BDNF-PAMAM solution was ultrafiltered with a membrane of $10 \mathrm{kDa}$ cutoff (Millipore, Amicon) to remove unconjugated PEG chains. This resulted in spontaneous self-assembly of BDNFPAMAM-PEG complexes that we will further refer to as "PEGylated PAMAM-based nanoparticles".

The particle size, zeta potential and polydispersity index (PDI) of BDNF, PAMAM 6, PAMAM 5.5, PAMAMbased nanoparticles, PEGylated PAMAM-based nanoparticles were determined with the Zetasizer Nano ZS apparatus (Malvern Instruments, Malvern, UK) equipped with a laser of $633 \mathrm{~nm}$ wavelengths. Data analysis was performed in automatic mode at $25^{\circ} \mathrm{C}$. Measured size was presented as the average value 
of 20 runs, with triplicate measurements within each run. Particle size distributions were obtained from measured diffusion coefficients.

The size distribution of PAMAM 6, PAMAM 5.5, PAMAM-based nanoparticles, PEGylated PAMAM-based nanoparticles was determined at mica surface by AFM (atomic force microscopy) technique. The nanoparticles were left to deposit on mica sheets (Continental Trade, Poland) placed in the diffusion cell over a $5 \mathrm{~min}$, and then substrate was removed and rinsed for half an hour in ultrapure water. The samples were left for air-drying until the next day. Next, the dry sample was placed under 7-10 nm AFM tip. The AFM measurements were carried out under ambient air conditions using the NanoWizard AFM (JPK Instruments AG, Berlin, Germany). The intermittent contact mode images were obtained in the air, using ultrasharp silicon cantilevers (NSC35/AIBS, MicroMash, Spain) and the cone angle of the tip was less than $20^{\circ}$. The images were recorded at the scan rate of $1 \mathrm{~Hz}$ for the six randomly chosen places. The images were flattened using an algorithm provided with the instrument. We captured all images in random areas within the scan size of $0.5 \times 0.5 \mu \mathrm{m}$ or $1 \times 1 \mu \mathrm{m}$. BDNF, PAMAM 5.5, PAMAM6, PAMAMbased nanoparticles and PEGylated PAMAM-based nanoparticles surface dimensions were determined using ImageJ software by gathering the number and coordinates of single protein/nanoparticles molecules.

\section{BDNF adsorption studies in PBS}

Protein loading profile at PAMAM-based nanoparticles and PEGylated PAMAM-based nanoparticles with negative charge core as well as positive charge core was conducted by solution depletion ELISA technique (DY992, DY990, DY994, DY999, DY995, WA126, DY006, DY268, R\&D Systems). Afterwards, to more accurately determine unbound BDNF after adsorption at PAMAM particles, two-step Laser Doppler Velocimetry (LDV) technique with the aid of the abovementioned Malvern device was used. LDV method exploiting the calibrating measurements uses various colloid particles (in our study modelled latex microparticles) for efficient monitoring of desorbed protein molecule concentration in order to determine protein maximum coverage at PAMAM nanoparticles.

\section{BDNF release studies in PBS}

The protein release profile from PAMAM-based nanoparticles, PEGylated PAMAM-based nanoparticles with negative charge core as well as positive charge core was assessed by using ultrafiltration method with a 30kDa cutoff membrane (Millipore, Billerica, MA, USA) in PBS at pH 7.4 and 0.15M ionic strength. It was done in two-stage procedure, where first BDNF adsorption process was carried out for $1 \mathrm{~h}$. The BDNF molecules released from nanoparticles with various charge core were quantified with ELISA immunoassay method according to the manufacturer's protocol. Initially, the residual (unbound) BDNF concentration in the filtrate was determined immediately after adsorption at PAMAM nanoparticles by applying sandwich ELISA technique to monitor the maximum concentration of unbound BDNF in the supernatant suspensions. Thus, it was possible to precisely determine concentration of non-adsorbed BDNF molecules at PAMAM as well as PEG-ylated PAMAM nanoparticle surface. These measurements 
were utilized for determining the maximum coverage of neurotrophin under protein bulk condition $(0.1$ $\mathrm{mgL}^{-1}$ ). Afterward, the concentration of desorbed BDNF for a $24 \mathrm{~h}$ was quantified with UV-VIS spectroscopy and calculated according to ELISA standard curve.

\section{Cell culture and differentiation}

SH-SY5Y neuroblastoma cells (human, ECACC; Sigma Aldrich, St. Louis, MO, USA) were used in this study. SH-SY5Y cells were incubated in culture plates in proliferation medium containing Ham's F-12 Nutrient Mixture (Thermo Fisher, Waltham, MA, USA) and minimum essential medium (MEM) (Sigma Aldrich, St.Louis, MO, USA) mixed in ratio 1:1 and supplemented with streptomycin $(100 \mu \mathrm{g} / \mathrm{mL})$, penicillin $(100 \mathrm{U} / \mathrm{mL})$, L-glutamine $(2 \mathrm{mM})$ and $15 \%$ heat-inactivated fetal bovine serum (FBS) at $37^{\circ} \mathrm{C}$ in saturated humidity atmosphere containing $5 \% \mathrm{CO}_{2}$. The proliferation medium was changed every $2-3$ days, and the cells were passaged when they reached $80 \%$ confluence. After the proliferation step, the cells were transferred into new culture plates and incubated for $24 \mathrm{~h}$ with MEM supplemented with penicillin $(100 \mathrm{U} / \mathrm{mL})$, streptomycin $(100 \mu \mathrm{g} / \mathrm{mL})$, L-glutamine $(2 \mathrm{mM})$ and $1 \% \mathrm{FBS}$. On the next day, the medium was changed to a differentiation medium consisting of MEM supplemented with penicillin (100 $\mathrm{U} / \mathrm{mL})$, streptomycin $(100 \mu \mathrm{g} / \mathrm{mL})$, L-glutamine $(2 \mathrm{mM}), 1 \%$ FBS and Retinoic Acid $(0.01 \mu \mathrm{mol} / \mathrm{mL})$ (RA, Sigma Aldrich, St.Louis, MO, USA). The differentiation was carried out for 5 days and the medium was changed every 2 days.

\section{6-OHDA and nanoparticles cytotoxicity}

Differentiated SH-SY5Y cells were incubated at a density of $3 \times 10^{4}$ cells/well in 96 -well plates for $24 \mathrm{~h}$ with MEM (without FBS) containing various concentration of 6-hydroxydopamine (20-35 $\mu \mathrm{mol} / \mathrm{L})$ (6-OHDA, Sigma Aldrich, St.Louis, MO, USA). 6-OHDA was freshly prepared for each experiment to avoid oxidation. $6-\mathrm{OHDA}$ remains the most widely used neurotoxin in Parkinson's disease (PD) in vitro models ${ }^{23}$, due to its structural similarity to dopamine (DA) and high affinity for the DA transporter, which enable it to selectively destroy dopaminergic neurons ${ }^{24}$. Therefore, for our study we chose to treat human neuroblastoma cell line SH-SY5Y with 6-OHDA, as it has been extensively described in the literature as a proper in vitro model for $\mathrm{PD}^{25,26}$. Cytotoxicity of 6-OHDA was evaluated by exposing cells to different concentrations of this neurotoxin for $24 \mathrm{~h}$ at $37^{\circ} \mathrm{C}$, and cell viability was estimated by the measuring toxicity using the MTT assay (Abcam, Cambridge, UK), which is based on the conversion of water soluble 3-(4,5-dimethylthiazol-2-yl)-2,5-diphenyltetrazolium bromide to an insoluble formazan product, which has a purple color. At the end of the treatments, the medium was discarded and new medium containing 0.5 $\mathrm{mg} / \mathrm{ml}$ was added. Cells were incubated with $50 \mu \mathrm{L}$ of MTT reagent mixed with $50 \mu \mathrm{l}$ MEM for $3 \mathrm{~h}$, then $150 \mu \mathrm{l}$ of detergent solution was added to solubilize the colored crystals. Finally, absorbance was measured at $590 \mathrm{~nm}$ using Varioskan LUX Multimode Microplate Reader (Thermo Fisher, Waltham, MA, USA). Toxicity was calculated from the equation provided in the manufacturer's protocol. 
After choosing certain 6-OHDA concentration, the cells were incubated for 24h with MEM (without FBS) containing $20 \mu \mathrm{mol} / \mathrm{L}$ of 6 -hydroxydopamine. At the end of the treatments, the medium was discarded and a following solution was added to each well: $20 \mu$ of PAMAM-based nanoparticles or PEGylated PAMAM-based nanoparticles with different charged core in PBS (described above in Preparation and

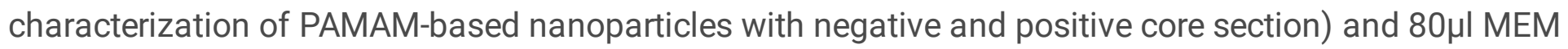
without FBS. The last step was to assess toxicity of various type of nanoparticles on differentiated SHSY5Y cells using the MTT assay.

\section{BDNF release studied in neuroblastoma cell culture exposed to 6-OHDA}

Concentration of released BDNF molecules was determined by exposing differentiated human neuroblastoma cells SH-SY5Y to 6-hydroxydopamine (6-OHDA) as well as nanoparticles with differently charged PAMAM core for $24 \mathrm{~h}$ at $37^{\circ} \mathrm{C}$. At the end of the treatments, the cell supernatant was discarded and collected to quantify BDNF concentration using UV-VIS spectroscopy calculated according to ELISA standard curve. Simultaneously we determined BDNF concentration in differentiated neuroblastoma cell lysate exposed to 6-OHDA what is crucial to enhancing nanoparticle efficacy. To obtain neuroblastoma cells exposed to $20 \mu \mathrm{mol} / \mathrm{L}, 6-\mathrm{OHDA}$ lysates $3 \times 10^{4} \mathrm{SH}-\mathrm{SY} 5 \mathrm{Y}$ cells were trypsinized and washed in medium twice and then followed by four freezes (liquid nitrogen) and thaw $\left(37^{\circ} \mathrm{C}\right.$ water bath) cycles. Large particles were removed by centrifugation $\left(2,000 \mathrm{~g}\right.$ for $10 \mathrm{~min}$, followed by $13,000 \mathrm{~g}$ for $60 \mathrm{~min}$ at $\left.4{ }^{\circ} \mathrm{C}\right)$ then lysate was filtered through a $0.22 \mu \mathrm{m}$ mesh and aliquots were stored at $-80^{\circ} \mathrm{C}$. The protein content was determined by the ELISA assay.

\section{PAMAM-based nanoparticles and PEGylated PAMAM-based nanoparticles behavior in cell culture}

In addition, we further investigated the behaviour of our nanoparticles loaded with BDNF in SH-5YSY cell culture by determination of green fluorescence of PAMAM-AF488 conjugates. Differentiated SH-SY5Y cells and previously treated with 6-OHDA (protocol described in 6-OHDA and nanoparticles cytotoxicity) were incubated at a density of $3 \times 10^{4}$ cells/well in 96-well plates with BDNF-PAMAM-AF488 and BDNFPAMAM-AF488-PEG nanoparticles $(0.1 \mu \mathrm{g} / \mathrm{mL}$ protein loading $)$ for $24 \mathrm{~h}$. After the nanoparticles labelled AF488 were removed, and the wells were washed twice with PBS, the cells were subjected to examinations by spectrofluorimetry evaluation using Varioskan LUX Multimode Microplate Reader.

\section{Flow cytometry}

To determine a mean fluorescence intensity (MFI) of nanoparticles PAMAM 5.5 and PAMAM 6 conjugated with fluorochrome AF488, the differentiated and treated with 6-OHDA cells SH-SY5Y (protocol described in 6-OHDA and nanoparticles cytotoxicity) were incubated at a density of $3 \times 10^{4}$ cells/well with PAMAM

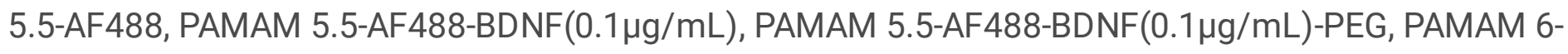
AF488, PAMAM 6-AF488-BDNF(0.1 $\mathrm{g} / \mathrm{mL})$ and PAMAM 6-AF488-BDNF( $0.1 \mu \mathrm{g} / \mathrm{mL})-P E G$ each in 10 separate repetitions for $24 \mathrm{~h}$. The cells were then washed with PBS, incubated for $3 \mathrm{~min}$ with trypsin, transferred to a cytometric tube, washed twice in PBS and resuspended in $200 \mu \mathrm{l}$ PBS. Fluorescence was 
measured and the data were analyzed using a LSRII flow cytometer (BD Biosciences) and the BD FACSDiva software. 10000 events were acquired to determine the MFI.

\section{Detection of lipid peroxidation}

Malondialdehyde (MDA) is the most abundant and stabile individual indicator of the level of the aldehydic products that can be produced from free radical attack on polysaturated fatty acids indicating lipid peroxidation present in cell cultures. The cells were incubated for $24 \mathrm{~h}$ with different concentration of BDNF, BDNF-PAMAM dendrimer nanoparticles or PEG-ylated BDNF-PAMAM dendrimer nanoparticles, adding $20 \mu \mathrm{l}$ to each well of selected solution prepared in PBS (described in Preparation and

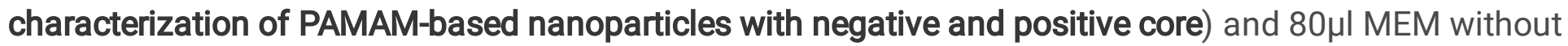
FBS. For this purpose, after completion of $24 \mathrm{~h}$ of incubation with various type of nanoparticles the cell supernatant was collected from each well $\left(3 \times 10^{4}\right.$ cells/well) for MDA analysis.

The MDA analysis in cell supernatant was determined using reverse-phase, high-performance liquid chromatography (HPLC)-spectrophotometric method according to Ref. ${ }^{27}$. HPLC (varian vista series) was performed on an Agilent Zorbax column (300A). Qualitative and quantitative analyses of MDA release by the differentiated human neuroblastoma cells SH-SY5Y threated 6-OHDA was performed by integrating the retention times and the peak areas compared with known concentrations of MDA standard prepared in the same solvent. 1,1,3,3-tetraethoxypropane (TEP) standards were freshly prepared daily. The solvent blank was absolute ethanol $(400 \mathrm{ml} / \mathrm{l})$ in distilled water. The stock standards were $10 \mathrm{mM}$ and $100 \mathrm{mM}$ TEP and the working calibrants were $0.0,0.25,0.50,0.75$ and $1.0 \mathrm{mM}$ TEP, prepared from dilution of the $100 \mathrm{mM}$ TEP with absolute ethanol $(400 \mathrm{ml} / \mathrm{l})$. The HPLC calibration was performed for each run. Samples were calculated as mM MDA equivalent from the TEP standard calibration (1:1 conversion under acidic conditions).

\section{Detection of mitochondrial membrane potential}

JC-1 (Caymanchem, MI,USA) is a lipophilic, cationic dye that can selectively enter into mitochondria. In healthy cells, JC-1 forms aggregates which display strong fluorescence intensity with excitation and emission at $535 \mathrm{~nm}$ and $595 \mathrm{~nm}$. In apoptotic/unhealthy cells, JC- 1 exists as monomers which show strong fluorescence intensity with excitation at $485 \mathrm{~nm}$ and emission at $535 \mathrm{~nm}$. Differentiated and treated with 6-OHDA cells SH-SY5Y (protocol described in 6-OHDA and nanoparticles cytotoxicity) were incubated at a density of $3 \times 10^{4}$ cells/well with PAMAM 5.5, PAMAM 6, PAMAM 5.5-BDNF $(0.02 \mu \mathrm{g} / \mathrm{mL})$, PAMAM 6-BDNF $(0.02 \mu \mathrm{g} / \mathrm{mL})$, PAMAM 5.5-BDNF(0.02 $\mu \mathrm{g} / \mathrm{mL})$-PEG, PAMAM 6-BDNF $(0.02 \mu \mathrm{g} / \mathrm{mL})-P E G$,

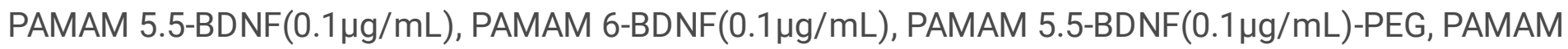
6-BDNF(0.1 $\mathrm{g} / \mathrm{mL})$-PEG, PAMAM 5.5-PEG, PAMAM 6-PEG, each in 16 separate repetitions for $24 \mathrm{~h}$. The

cells were then incubated with $\mathrm{JC}-1$ Staining Solution for $15 \mathrm{~min}$ in a $\mathrm{CO}_{2}$ incubator at $37^{\circ} \mathrm{C}$ according to the manufacturer's protocol. Fluorescence was measured with Ex535nm/Em595nm and Ex485nm/Em535nm using a Varioskan Lux Reader (Thermo Fisher Scientific, MA, USA). The ratio of 
fluorescence intensity of aggregates to fluorescence intensity of monomers was used as an indicator of cell health.

\section{Confocal microscopy}

To determine the morphological changes the SH-SY5Y cells were seeded at a density of $1 \times 10^{5}$ cells/well in a 4-well chamber slide, differentiated with RA and treated with 6-OHDA. Next, the cells were incubated with: PAMAM 5.5, PAMAM 5.5-PEG, PAMAM 5.5-BDNF $(0.1 \mu \mathrm{g} / \mathrm{mL})$, PAMAM 5.5-BDNF $(0.1 \mu \mathrm{g} / \mathrm{mL})-P E G$, PAMAM 6, PAMAM 6-PEG, PAMAM 6-BDNF $(0.1 \mu \mathrm{g} / \mathrm{mL})$ and PAMAM 6-BDNF $(0.1 \mu \mathrm{g} / \mathrm{mL})$-PEG for 24 hours. Subsequently, the cells were fixed with $70 \%$ ethanol for 15 min and washed twice with PBS. For cell membrane staining the slides were incubated with 1:100 wheat germ agglutinin-Texas Red $X$ (ThermoFisher, Waltham, MA, USA) in HBSS buffer for 20 min. After washing the slides were counterstained with DAPI, mounted and examined using Carl Zeiss LSM 700 microscope (Zeiss, Jena, Germany). The cell nuclei dimensions were measured at their widest point using ZEN software. For each specimen at least 200 measurements were taken.

\section{Statistical analysis}

All presented data are expressed as means +/- standard deviation (SD) from at least three independent experiments. Statistical analysis among each study group was performed using Kruskal-Wallis test. TwoWay ANOVA was used for analysis between experimental groups. $p<0.05$ was considered statistically significant.

\section{Results}

\section{Characterization of PAMAM- and PEGylated PAMAM-based nanoparticles with differently charged PAMAM cores}

To understand the BDNF release mechanism, we examined the physical characteristics of this encapsulation-free release system - on the basis of particle size, polydispersity index (PDI), zeta potential, drug loading (DL)\%, and encapsulation efficiency (EE)\%. PAMAM-based nanoparticles size was characterized by atomic force microscopy (AFM) and dynamic light scattering (DLS). DLS studies indicated that all nanoparticles preparations were under $13 \mathrm{~nm}$ in hydrodynamic diameter and had an optimal polydispersity index of less than 0.4. PAMAM-based nanoparticles with negatively and positively charged core were spherical, with an average diameter of $9 \pm 1 \mathrm{~nm}$, and a polydispersity index of $0.4 \pm$ 0.15 measured by DLS (Fig. 1A). DLS analysis for PEGylated PAMAM-based nanoparticles with negatively and positively charged core revealed a mean diameter of $12+/-1.1 \mathrm{~nm}$, with a relatively low PDI of less than 0.22. As shown in Figure 1A, the mean hydrodynamic diameter value obtained for BDNFPAMAM nanoparticles were significantly lower from the PEG-ylated ones as opposite to PDI value showing that PEG-functionalization influences the average size and polydispersity of the nanoparticles. The PDI and hydrodynamic diameter of the nanoparticles over time are shown in Figure 1, A and C respectively. All PAMAM-based nanoparticles with negatively and positively charged core showed size 
stability in the presence of serum. Fluctuations in nanoparticle hydrodynamic diameter were within the range of $15 \mathrm{~nm}$ in all sample groups at the end of 30 days. The PDI of PEG-ylated groups was also maintained at less than 0.2 , indicating that they remained in the monodisperse state without forming aggregates over the same time period. As protein/drug delivery systems, all tested PAMAM-based nanoparticles remained stable at high salt concentration for over 30 days. Therefore, this spontaneous self-assembly nanocomplex can be used as an injectable pharmaceutical agent without sonication or other extensive agitation.

Using AFM, we could visualize an average nanoparticle diameter on the mica surface as well as the size range of nanoparticles adsorbed under the diffusion-controlled transport condition at $\mathrm{pH} 7.4$ and an ionic strength 0.15M. AFM (Figure 1B) suggested that PAMAM-BDNF-PEG nanoparticle was around $9 \pm 2 \mathrm{~nm}$ in diameter and was smaller than PAMAM-BDNF formed nanoparticles with diameter of $11 \pm 2 \mathrm{~nm}$. AFM studies revealed that all tested nanoparticles were spherical and distributed on the mica surface uniformly without adhesion or aggregation. This enabled us to exactly determine their sizes by cutting down the possibility of tip convolution artifacts.

Afterwards, the prepared BDNF-PAMAM as well as PEG-ylated BDNF-PAMAM nanoparticles were physicochemically characterized in terms of electrophoretic mobility/zeta potential in PBS buffer without calcium and magnesium ions. The BDNF adsorption on positively and negatively charged PAMAM dendrimers core at $7.4 \mathrm{pH}$ and $0.15 \mathrm{M}$ ionic strength proceeds according to the bulk diffusion control transport mechanism. The experimental data showed surface charge stability of PAMAM core, BDNFPAMAM as well as PEG-ylated BDNF-PAMAM nanoparticles obtained in the primary adsorption experiments (shown in Figure 1C) with initial concentration of BDNF $0.1 \mathrm{mgL}^{-1}$ in the suspension (after mixing). Zeta potential measurements showed that the core of the PAMAM 5.5 was negatively charged $(-26 \mathrm{mV} \pm 5.2 \mathrm{mV})$, increasing with BDNF adsorption up to $-19 \mathrm{mV} \pm 4.2 \mathrm{mV}$. PEG adsorption at BDNFPAMAM nanoparticles increased zeta potential value even more (to $-10 \mathrm{mV} \pm 4.5 \mathrm{mV}$ ), probably because of a reduction in the number of charged groups on the nanoparticle surface if they are, in part, utilized as anchoring points for PEG binding or due to chelation of cations by the PEG chains. On the other hand, zeta potential of PAMAM 6 was positive $(25 \mathrm{mV} \pm 2.1 \mathrm{mV})$, decreasing up to $-11 \mathrm{mV} \pm 3.2 \mathrm{mV}$ after adsorption of slightly positively charged BDNF molecules $(5 \mathrm{mV} \pm 2.5 \mathrm{mV})$. The observed significant adsorption of positively charged molecule on positively charged surface at above mentioned bulk conditions is anomalous from the mean-field Gouy-Chapman theory. As discussed in Refs. ${ }^{28,}{ }^{29}$ this can be explained by highly heterogeneous charge distribution over the BDNF molecule or conformational changes in the protein structure. It can be noted that for $0.1 \mathrm{mgL}^{-1} B D N F$ concentration, the change in zeta potential of PAMAM 6 dendrimer (positively charged core) is significant, whereas in case of PAMAM 5.5 dendrimer (negatively charged core) there is just a slight change in the zeta potential. Irrespectively of the initial dendrimer core charge, PEG-ylation of the PAMAM-BDNF surface significantly increases the zeta potential of the nanoparticle. In case of PAMAM 6, PEG-ylation of the PAMAM-BDNF nanoparticles neutralizes the initial charge of the particle, as the zeta potential approaches the value close to $-2.5 \mathrm{mV} \pm$ $1.5 \mathrm{mV}$. 


\section{BDNF loading and releasing from PAMAM- and PEGylated PAMAM-based nanoparticles with differently charged PAMAM cores in PBS buffer}

In order to determine the possibility of desorption from PAMAM- as well as PEGylated PAMAM-based nanoparticles with differently charged PAMAM core, once adsorption reached equilibrium and before the in vitro release profile was performed, we studied the BDNF release in PBS buffer.

Initially, adsorption of slightly positively charged BDNF molecules to negatively as well as positively charged PAMAM dendrimers core surfaces was precisely determined to control the concentration of unbounded protein molecule and protein-laden nanoparticles structure. For every tested system, the saturation concentration of the protein had to be determined empirically. PAMAM nanoparticle was characterized with significant changes in its apparent zeta potential during adsorption, which we efficiently monitored using DLS method. After loading of BDNF into PAMAM-based nanoparticles, we determined the dependence of the zeta potential of nanoparticles on the initial concentration of BDNF in the PAMAM suspension (after mixing). As is depicted in Figure 2A, for adsorption at PAMAM 5.5, the PAMAM-BDNF zeta potential slightly increases with increasing BDNF concentration and approaches the value of $-19 \mathrm{mV}$, which is considerably below the zeta potential of BDNF molecules determined in the bulk ( $5 \mathrm{mV}$ at $0.15 \mathrm{M}$ ionic strength). For the range of tested BDNF concentrations $\left(0.1-100 \mathrm{mg} \mathrm{L}^{-1}\right)$, the zeta potential of the BDNF is rather stable. Importantly, at pH 7.4 BDNF molecules carry a net positive charge and adsorb onto negatively charged uniform surface according to the mean-field theory, because both BDNF and PAMAM core exhibit opposite sign of zeta potentials. Moreover, the electrophoretic mobility of BDNF-PAMAM 5.5 core dendrimers is far from the value obtained for electrophoretic mobility of BDNF in the bulk and it corresponds to the formation of unsaturated BDNF structures on PAMAM cores. As is depicted in Figure $2 \mathrm{~B}$, zeta potential of PAMAM 6 dendrimers abruptly decreases with BDNF adsorption. It is quite unexpected as BDNF zeta potential was equal to $+5 \mathrm{mV}$, and PAMAM surface was also strongly positive, having zeta potential of $+25 \mathrm{mV}$. According to our knowledge, our study for the first time shows such an anomalous BDNF-PAMAM 6 interaction, although similar behaviour of different proteins deposition under physiological conditions have been previously observed by Wasilewska et al. ${ }^{29}$, Malmsten ${ }^{30}$, Ortega-Vinuesa et al. ${ }^{31}$ Toscano and Santore ${ }^{32}$, Kalasin and Santore ${ }^{33}$, and others. Overall, the experimental results shown in Figures $2 \mathrm{~A}$ and $\mathrm{B}$ suggest that an electrostatically driven adsorption of BDNF at PAMAM can be expected for both positively and negatively charged dendrimer cores and slightly positively charge BDNF molecules. This hypothesis was checked experimentally, as described below.

We used ELISA to determine residual (free) BDNF concentration after adsorption at PAMAM core dendrimers with opposite surface charge as well as after PEGylation of PAMAM-BDNF nanoparticles (Figure 2C). As can be observed, for low initial BDNF concentration $\left(0.1 \mathrm{mg} \mathrm{L}^{-1}\right)$, concentration of unbounded protein molecules in PBS were negligible, indicating that adsorption onto $50 \mathrm{mg} \mathrm{L}^{-1}$ of PAMAM nanoparticles was almost complete. Concentration of unbounded BDNF protein was higher in the case of BDNF-PAMAM5.5 than BDNF-PAMAM6 nanoparticles, which correlates with the dendrimer charge. As discussed elsewhere ${ }^{34}$, knowing the electrophoretic mobility one can calculate the average 
number of free charges per protein molecule expressed in coulombs from the Lorenz-Stokes relationship under physiological conditions. The value of the uncompensated charge per BDNF molecule reaches $0.9 \mathrm{e}$ (the BDNF molecule acquired a net positive charge which is around three times smaller than for HSA). Under these conditions, double-layer forces were remarkably weak due to decreasing protein net charge, which indeed enhances the possibility of BDNF aggregation for this $\mathrm{pH}$ range in accordance the hydrodynamic diameter measurements of native BDNF (not shown). According to Jiang et al. ${ }^{35}$, BDNF forms large and highly heterogenous aggregates with an effective diameter of $600 \mathrm{~nm}$ and PDI greater than 0.4. and, thus in this form it cannot be used as an injectable drug agent. Our approach resolves this problem by mixing BDNF and PAMAM in appropriate concentrations and using simple electrostatic interactions between BDNF molecules and PAMAM surfaces which indeed hampers the possibility of BDNF aggregation, in accordance with the aforementioned measurements of the hydrodynamic diameter (Figure 1B). In case of PEG-ylated nanoparticles, the residual BDNF concentration after adsorption is lower than in unPEG-ylated nanoparticles which might suggest that after the adsorption at PAMAM, the remaining scarce unbound BDNF molecules are PEG-ylated.

\section{Nanoparticle's toxicity}

In order to determine the possibility of toxicity of PAMAM-based nanoparticles with differently charged PAMAM core in biomedical applications, we examined viability of a differentiated neuroblastoma $\mathrm{SH}-$ SY5Y cells previously exposed to 6-OHDA and then administered nanoparticles. First and foremost, we differentiated SH-SY5Y cells by a combination of RA treatment and lowering FBS concentration in cell culture according to our previous report ${ }^{36}$. To establish experimental dosage of 6-OHDA for testing toxicity of PAMAM- and PEGylated PAMAM-based nanoparticles with differently charged PAMAM cores, we examined differentiated SH-SY5Y cells' responsiveness to various concentrations of 6-OHDA for 24h using two complementary methods: MTT assay and flow cytometry (Supplementary materials). The reduction of cell viability was employed here as an indicator of cell proliferation and nanoparticle toxicity. We established that exposure to $20 \mu \mathrm{mol} / \mathrm{L} 6-\mathrm{OHDA}$ resulted in a significant $20 \%$ decline in cell viability. For further studies we chose this dose of 6-OHDA to determine the cytotoxicity of PAMAM, PAMAM- and PEGylated PAMAM-based nanoparticles with differently charged PAMAM cores on differentiated SHSY5Y cells after $24 \mathrm{~h}$ of incubation (Fig. 3 ).

As we observed, the nanoparticles with negatively charged PAMAM core (5.5 generation) lead to higher cell viability of differentiated human neuroblastoma cell line SH-SY5Y treated with the 6-OHDA neurotoxin in vitro. The MTT assay demonstrated that $10 \mathrm{mgL}^{-1}$ of PAMAM 5.5 dendrimers significantly increases cell viability, whereas positively charged PAMAM 6 dendrimers significantly decrease cell viability in comparison with control (Supplementary Materials). The data presented in Figure 3 further shows that 24h incubation of neuroblastoma cells with PAMAM-BDNF nanoparticles with negatively charged core increases cell viability from $112 \%$ (initial value obtained for PAMAM 5.5 without BDNF) to $137 \%$ in case of PAMAM 5.5-based nanoparticles. Moreover, after adsorption of $25 \mathrm{mgL}^{-1}$ PEG at nanoparticles with negatively charged dendrimer core, a distinct decrease in metabolic cell activity (almost up to values observed in control) was observed in comparison to PAMAM5.5 and PAMAM 5.5- 
BDNF nanoparticles. On the contrary, a similar decrease in cell viability was observed for positively charged PAMAM6, PAMAM6-BDNF and PEGylated PAMAM6-BDNF compared to controls, suggesting that nanoparticles with positively charged core are less biocompatible with differentiated cells and presumably show non-specific toxicity. This indicates that positively charged PAMAM core dendrimer markedly decreases in vitro cellular viability in the presence of neurotoxin.

\section{In vitro BDNF release profile from PAMAM- and PEGylated PAMAM-based nanoparticles with differently charged PAMAM cores}

Next, we aimed to determine whether BDNF from dendrimer-based nanoparticles is sustainably released in the in vitro setting. Thus, we investigated the suitability of negatively and positively charged PAMAM dendrimers and PAMAM- and PEGylated PAMAM-based nanoparticles with differently charged PAMAM cores to effectively transport BDNF to differentiated neuroblastoma cells exposed to 6-OHDA. To assess the distribution of applied various dendrimer-neurotrophin conjugates, we analyzed BDNF concentrations in cell lysates as well as culture supernatant using ELISA after $24 \mathrm{~h}$ post-treating. The cells exposed to RA and $20 \mu \mathrm{mol} / \mathrm{L} 6-\mathrm{OHDA}$ served as controls. The results are summarized in Figure 4.

In supernatants from control cells BDNF was released at the concentration of $4 \mathrm{ngL}^{-1}$. Interestingly, we observed that application of positively as well as negatively charged dendrimers ( 6 and 5.5 generation, respectively) to the cell culture significantly decreased BDNF concentration in cells supernatant (Figure 4). There was no detectable BDNF concentration in cell lysates neither in controls nor after treating with PAMAM 5.5 or PAMAM 6 dendrimers. We also observed that BDNF concentration in cell supernatant was significantly lower in case of PAMAM5.5- compared to the PAMAM6-based nanoparticles.

As can be seen in Figure 4, PEG-ylation of nanoparticles, regardless of the dendrimer core charge, leads to a decrease in BDNF concentration in supernatant, whereas in cell lysates there is no such result of PEGylation. For BDNF release profile in PBS from PEG-BDNF-PAMAM nanoparticles with PAMAM 5.5 dendrimer core after $24 \mathrm{~h}$ of treating, we observed significantly higher desorption of BDNF compared to nanoparticles with PAMAM 6 dendrimer core (Figure 2C). On the other hand, in in vitro setting, we found that BDNF desorption from the nanoparticles based on negatively as well as positively charged dendrimers core are in opposite to the aforementioned release profile presented in PBS (Figure 4).

\section{Cellular uptake of PAMAM- and PEGylated PAMAM-based nanoparticles with differently charged PAMAM cores}

Cellular uptake of PAMAM 5.5-AF488 (no BDNF), PAMAM 5.5-AF488-BDNF, PAMAM 5.5-AF488-BDNFPEG, PAMAM 6-AF488 (no BDNF), PAMAM6-AF488-BDNF-, PAMAM 6-AF488-BDNF-PEG in differentiated human neuroblastoma cell line SH-SY5Y treated with 6-OHDA was examined through spectrofluorimetry with a fixed concentration of BDNF $\left(0.1 \mathrm{mg} \mathrm{L}^{-1}\right)$. As shown in Fig. $5 \mathrm{~A}$ and $\mathrm{B}$, PAMAM dendrimers without protein, PAMAM- as well as PEGylated PAMAM-based nanoparticles with differently charged cores seem rather coated on SH-SY5Y cell surface than internalized by cells after $24 \mathrm{~h}$ of incubation. As shown in Figure $5 \mathrm{~A}$ and $\mathrm{B}$, there was observable change in green fluorescence intensity for PAMAM-AF488 
dendrimers compared to control cells without carriers which suggests that NPs can effectively be adsorbed on cells membrane. However, PAMAM5.5-AF488 and PAMAM6-AF488 show different fluorescence intensity due to the varying functional groups on their surfaces and this results in differences in fluorescent labelling efficiency. Therefore, PAMAM 5.5 and PAMAM 6 cannot be directly compared in case of cellular uptake. As can be seen in Figure 5, PEG-ylation of nanoparticles results in lower of green fluorescence intensity than for NP without PEG such as PAMAM-BDNF, and PAMAM alone for both type of dendrimer.

This suggests that protein molecules encapsulated in polyelectrolyte can be effectively protected and this prevents non-specific adsorption compared to dendrimer itself. Due to the limitations of spectrofluorimetry method, we were unable to unequivocally assess whether nanoparticles have in fact entered the cells or not, thus we used flow cytometry to further investigate this matter. Flow cytometry analysis was carried out to better understand the cellular uptake efficiency of the developed NPs. As seen in Figure $5 \mathrm{C}$ and D, PAMAM-based nanoparticles harboring BDNF presented more pronounced green fluorescence than PAMAM dendrimers without BDNF.

\section{Morphological alteration induced by PAMAM- and PEGylated PAMAM-based nanoparticles with differently charged PAMAM cores}

The WGA fluorescence staining was used to assess the state of differentiation of SH-SY5Y cells after the treatment with PAMAM 5.5, PAMAM 5.5-PEG, PAMAM 5.5-BDNF $(0.1 \mu \mathrm{g} / \mathrm{mL})$, PAMAM 5.5-BDNF $(0.1 \mu \mathrm{g} / \mathrm{mL})$-PEG, PAMAM 6, PAMAM 6-PEG, PAMAM 6-BDNF $(0.1 \mu \mathrm{g} / \mathrm{mL})$ and PAMAM 6-BDNF $(0.1 \mu \mathrm{g} / \mathrm{mL})-P E G$. The cells incubated with PAMAM 5.5, with the nanoparticle itself as well as with the PEG-ylated form, retained their differentiated shape with elongated processes (Figure 6A). On the other hand, cells treated with various forms of PAMAM 6 - alone, PEG-ylated or with BDNF - presented serious phenotype alterations. These cells were round, significantly smaller and did not show the characteristic features of neural cells when compared to differentiated control or PAMAM 5.5 treated cells. Moreover, the nuclei size distribution analysis revealed a major difference between cells incubated with differentially charged nanoparticles (Figure 6B and C). In SH-SY5Y cells subjected to PAMAM 6 and all its tested modifications the cell nuclei dimensions were smaller than in PAMAM 5.5 treated or control cells. Interestingly, the nuclei of SH-SY5Y cells incubated with PAMAM 5-BDNF $(0.1 \mu \mathrm{g} / \mathrm{mL})$-PEG were slightly but significantly bigger than in control specimens.

\section{Detection of mitochondrial dysfunction and lipid peroxidation in neuroblastoma cell line after treating with PAMAM- and PEGylated PAMAM-based nanoparticles with differently charged PAMAM cores}

Based on above results related to stimulation of neuronal-like cell proliferation and survival, we investigated whether PAMAM-based NPs can trigger oxidative damage through inducing reactive oxygen species (ROS) accumulation and if a trophic factor, BDNF, released by PAMAM-based NPs could induce oxidative stress by altering composition of cellular membrane lipids as well as mitochondrial membrane potential of the human SH-SY5Y cell line. Several major events occur in mitochondria in response to oxidative stress, of which, the most significant is the loss of mitochondrial membrane potential (MMP) 
leading to apoptosis. To elucidate the role of mitochondria in NPs-induced apoptosis of SH-SY5Y cells, we detected depolarization of MMP using JC-1. As shown in Fig. 7a, treatment of NPs with PAMAM 6 (for $24 \mathrm{~h}$ ) induced significant loss of MMP, as reflected by the fluorescence shift from red to green. A decrease in the red $(\sim 590 \mathrm{~nm}) /$ green $(\sim 529 \mathrm{~nm})$ fluorescence intensity ratio by exposure to PAMAM-based NPs is indicative of depolarization/disruption of the mitochondrial membrane in previously differentiated human neuroblastoma cells. PAMAM 5.5-BDNF-PEG treatment improved the MMP ( $120 \%$ of control MMP) in SHSY-5Y cells compared to the control (100\% MMP), whereas all other tested dendrimers and PAMAM-based NPs can cause mitochondrial fragmentation, as demonstrated by Figure 7a.

In order to further investigate the molecular mechanism of oxidative stress related to the different mitochondrial membrane depolarization found after treatment with PAMAM5.5 and PAMAM 6, we examined the levels of MDA-(TBA) ${ }_{2}$ complex, which is the marker of lipid peroxidation (Figure 7B). The separation of the MDA-(TBA $)_{2}$ complex from other interfering compounds by reverse phase HPLC technique and we observed a more pronounced reduction in MDA levels in PAMAM 5.5 and PAMAM 5.5based nanoparticles in comparison to PAMAM6 and PAMAM6-based NPs. MDA ranges in control cells were determined to be as low as $20 \mathrm{nM}$, which is more than a fourfold increase from PAMAM 5.5. The concentrations of MDA in cell supernatant after PAMAM 6 treatment were $85 \mathrm{nM}$ and increased to 198 nM for PAMAM 6 - BDNF nanoparticles. There were significant differences between PAMAM -BDNF nanoparticles compared to those with PEG layer for both generations of PAMAM dendrimers.

\section{Discussion}

Recently, various compounds and preparation methods have been explored to improve stability and water-solubility of polymeric drug delivery systems which enable sustained and efficient delivery of therapeutic protein over prolonged periods, leading to the formulation of $\mathrm{DNA}^{37}$, chitosan, polyelectrolytes ${ }^{38}$, pyrrole, silica, gold, cells and dendrimer-based nanoparticles. Cytotoxicity of active core of NP and its poor cellular internalization are among the most important factors that contribute to unfavourable side effects caused by noneffective active compound delivery. Despite the large number of studies $^{18,39,40}$, the application of dendrimers in biomedicine is rather difficult due to a lack of understanding of the relationship between physicochemical properties of protein-based dendrimer NP and the mechanism of their cellular uptake and cytotoxicity. In the present study, we focused on the electrokinetic charge of PAMAM dendrimers in constructing (PEGylated)PAMAM-BDNF nanoparticles with the use of physicochemical approach which constitutes the most significant parameter affecting PAMAM-based nanoparticles in vitro toxicity, biopermeability and oxidative stress properties.

It has been reported that charged ligands can prevent or enhance linking chemistry via electrostatic repulsion or attraction and dramatically affect non-specific interaction/adsorption ${ }^{40-42}$. We found that NPs with tailored charge properties could allow/improve protection of BDNF from nonspecific binding with serum proteins and could enable controlled delivery of BDNF in two manners: 1) indirectly via reversibly adsorbed BDNF molecules at NPs surface or 2) directly via NPs and irreversibly bound BDNF. 
Similar finding was proposed for another nanoscale complex of polymer poly(ethylene glycol)-b-poly(Lglutamic acid) with BDNF protein where molecular dynamics simulations suggest that binding between BDNF and PEG-PLE is mediated through electrostatic coupling as well as transient hydrogen bonding. In this study, Yuhang Jiang et al. suggested that poor intranasal-to-brain bioavailability of BDNF can be attributed to its cationic surface charges and extensive binding to a variety of polysaccharides, resulting in its entrapment and degradation within the negatively charged tissues ${ }^{35}$.

In our study, the electrophoretic mobility of the BDNF-PAMAM nanoparticles was much lower than the electrophoretic mobility of bulk protein, which corresponded to the formation of an unsaturated BDNF layer on PAMAM as well as structural alterations/conformation change of BDNF that can be induced upon NP-binding. It has been shown by various theoretical calculations performed using the chemical composition of proteins that the surface charge of the molecule is heterogeneously distributed in the form of positive and negative patches, existing over a wide range of $\mathrm{pH}$. This hypothesis is supported by analogous results reported in the literature on proteins: $\mathrm{HSA}^{43}, \operatorname{lgG}^{44}$, fibrinogen ${ }^{45}, \mathrm{NT}-4^{34}$ and lysozyme ${ }^{46}$.

We carried out BDNF adsorption at PAMAM dendrimers in high ionic strength $(0.15 \mathrm{M})$ solution, because the reduction of the repulsive interactions between the protein and polymers has been previously reported for different proteins, including polyclonal rabbit immunoglobulin $(\operatorname{lgG})^{47}$, fibrinogen ${ }^{45}$, albumin ${ }^{43}$ and NT$4^{34}$. By applying this approach, we obtained higher adsorbed amount of BDNF which makes our nanocarriers more biocompatible.

Our previous study ${ }^{48}$ showed that the maximum coverage of the irreversibly bound protein increases monotonically with increasing ionic strength - this directly translates to our current study, in which range between BDNF and PAMAM molecules, determining lateral electrostatic interaction, decreases proportionally to the double layer thickness (according to Debye length: $1 /(\text { kappa } a)^{1 / 2}$ (a is a characteristic protein dimension and $\mathrm{k}^{-1}$ Debye screening length)), which is correlated with ionic strength of solution. One can speculate that this effect is caused by additional interactions, most likely of the van der Waals type or hydrogen bonding described elsewhere ${ }^{49,50}$.

Another contribution to attractive interactions at this $\mathrm{pH}$ may originate from the heterogeneous charge distribution over the BDNF molecule, which in our study was suggested by slightly positive charge of protein at $\mathrm{pH}$ 7.4. Therefore, even if the overall charge of the BDNF molecule remains positive, there are patches bearing negative charge. It should be mentioned that anomalous protein deposition under physiological conditions was previously observed for various protein e.g. fibrinogen by Wasilewska and Adamczyk $^{29}$, Malmsten ${ }^{30}$, Ortega-Vinuesa et al. ${ }^{31}$,Toscano and Santore ${ }^{32}$, albumins and neurothrophins ${ }^{33}$. Based on the abovementioned findings, here we show that BDNF adsorption at the PAMAM dendrimers with anionic (sodium carboxylate) and cationic (amine) terminal groups is significant, which is consistent with a binding mechanism which involves weak interactions between dendrimer terminal groups and the BDNF amino acids residues. Our observation of these effects of 
dendrimer terminal group chemistry on the protein adsorption on PAMAM dendrimers is in accordance with the results reported by Bo Wang et al. ${ }^{41}$, where areas of HSA with many acidic residues were attached to the positively charged binding sites on PAMAM. We observed a low residual protein concentration after adsorption which reflects that for negatively charged PAMAM the BDNF amino acid residues are slightly protonated, positively charged and attached to PAMAM, whereas for positively charged PAMAM the BDNF amino acid residues are slightly deprotonated, negatively charged and attached to PAMAM. This suggests that electrostatic interactions are crucial in binding of charged dendrimers with proteins, which has also been observed for chymotrypsin, $\lg ^{41}$ and cytochrome- $\mathrm{c}^{51}$.

Moreover, we noticed that the adsorption of BDNF molecules on dendrimer nanocarrier, regardless of its surface electrokinetic charge, prevents protein aggregation and thus could enable interaction with the receptors, making them more biocompatible and suitable for a range of biomedical applications. Yuhang J. et al. also observed that the BDNF self-assembles with anionic block copolymers into nanosized complexes, stabilized by cooperative electrostatic interaction and $\mathrm{H}$-bonds were nearly monodispersed at specific charge ratios ${ }^{35}$. These findings are in good agreement with previous studies for interaction of dendrimer with human serum albumin ${ }^{52}$ and intracellular ion ${ }^{53}$.

The surface chemistry of dendrimers has been found to influence their cytotoxicity which varies between cell types as well as dendrimers functionalization with $-\mathrm{OH},-\mathrm{COOH},-\mathrm{NH}_{2}$ terminal groups, PEG-ylation ${ }^{54}$, 55 . The variations in cell response found in cytotoxicity studies, can be determined by different physicochemical properties of PAMAM dendrimers and their interactions with cell membranes which remains poorly understood ${ }^{18}$. The cytotoxicity of PAMAM dendrimers as a result of the interactions between positively charged dendrimers and negatively charged protein or cell surface was described by Wei Wang at al. ${ }^{39}$ That findings are in good agreement with our results that strongly suggest that electrostatic interaction of positively charged PAMAM 6 dendrimers with cell membranes decreases their viability as well as increases serious phenotype alterations in comparison to negatively charged PAMAM 5.5 dendrimers. We also have shown that there was only a little change in cell viability or phenotype alteration of tested cells when they were exposed to a modified PAMAM 6 dendrimers (originally positively charged) by adsorption of BDNF or PEG even if the charged groups on the dendrimers surface was neutralised and gave nominally uncharged NP. In our study, after PEG adsorption at negatively charged PAMAM-BDNF nanoparticles, the zeta potential of saturated PEG layers displayed negative value. This suggests that the surface at the base of the brush is net negative and that the shear plane for zeta potential study lies substantially beneath the brush height. This could be related to a shift of the hydrodynamic phase of shear to lower distances of the nanoparticles surface. Similar observations have been previously described elsewhere ${ }^{56-58}$.

It has been established that dendrimers' cytotoxicity depends on the generation and concentration of the dendrimer and varies with cell types ${ }^{18,59}$. One of the key factors that determines the toxicity of several nanomaterials, including dendrimers, is oxidative stress ${ }^{60,61}$. Reactive oxygen species (ROS) formation causes damage to biological components through oxidation of lipids, proteins and DNA damage, finally 
leading to apoptosis ${ }^{62}$. Mukherjee et al. have proposed that the cationic PAMAM dendrimers enter the cell via endocytosis and are transported in endosomes and localise in mitochondria ${ }^{63}$. Next, the dendrimers induce an increase of mitochondrial internal $\mathrm{pH}$ due to an acid-base equilibrium reaction between secondary amines and their conjugate base, resulting in the production of ROS. In our study we found significantly increased levels of malonylodialdehyde (MDA) after PAMAM6-based nanoparticles administration in comparison to the PAMAM5.5-ones. This further supports this notion of positively charged PAMAM6 effects on ROS generation, as MDA is an end-product of PUFAs (polyunsaturated fatty acids) oxidation and it serves as an indicator of lipid peroxidation and oxidative stress ${ }^{64}$. Interestingly, we observed that the functionalisation of PAMAM dendrimers with PEG reduces MDA concentration. The reduction of cytotoxicity with PEG addition has been previously described by several groups and is generally attributed to changes of dendrimer surface charge that influence interactions with cellular membranes ${ }^{65,66}$.

Oxidative damage is also linked with mitochondrial dysfunction, which includes changes in the membrane potential and alterations to the oxidation-reduction potential of the mitochondria ${ }^{67}$. In our study, we found that the detrimental cellular effect of PAMAM6-based NPs administration was reflected also in induction of mitochondrial depolarization, whereas exposure to PAMAM 5.5-BDNF-PEG induced a significant increase of mitochondrial membrane potential. Nyitrai et al. have described a prominent mitochondrial membrane depolarization in pyramidal neurons and astroglial rat cells after exposure to PAMAM5, which they have attributed to the enhancement of intracellular $\mathrm{Ca}^{2+} l$ evel $^{68}$. Interestingly, when dendrimer was administered together with $\mathrm{Ca}^{2+}$, the protective effects against mitochondrial depolarization caused by calcium ions was observed ${ }^{69}$. As Janaszewska et al. have noted, PAMAM functionalisation (in that case with 4-carbomethoxypyrrolidone) resulted in lack of influence of the PAMAM-pyrrolidone dendrimer on intracellular ROS level and mitochondrial membrane potential ${ }^{59}$. This suggests that our results of improved MMP in case of PAMAM5.5-PEG, could be attributed to beneficial influence of PEG on the nanoparticle surface, which results in favourable effect on mitochondrial membrane potential.

\section{Conclusions}

We provide characterisation of efficient encapsulation of BDNF into PEG-ylated-PAMAM complex with anionic or cationic core charge, with a particular focus on electrostatical interactions in the constructed nanoparticles and their behaviour in differentiated human neuroblastoma cell line SH-SY5Y treated with 6-OHDA. The key finding of our study was that PAMAM5.5 and PAMAM6 dendrimer-based nanoparticles differ significantly in terms of BDNF release profile from their surfaces and their effect on cell viability, mitochondrial membrane potential, cell phenotype and induction of oxidative stress. Our results confirm that the design of nanoparticles for biological applications requires thorough understanding and consideration of electrostatical interactions between components of the nanoparticle.

\section{Declarations}


Supporting information

Determination of the cytotoxicity of 6-OHDA on differentiated human neuroblastoma SH-SY5Y cells after $24 \mathrm{~h}$ of incubation with the flow cytometry and MTT assay.

\section{Authors' contribution}

K.t. preparation of cell culture, D.R. confocal microscopy experiments, M.W. DLS and AFM microscopy experiments, M.D. data analysis and manuscript writing; M.O and K.J. MDA analysis; A.S. graphics preparation; Z.U. and B.M. manuscript supervision.

\section{Funding}

This work was supported by the National Centre for Research and Development grant STRATEGMED1/234261/2NCBR/2014.

\section{Author information}

Maria Dąbkowska is corresponding author

Affiliations

${ }^{1}$ Department of Medical Chemistry, Pomeranian Medical University, Rybacka 1, 70-204 Szczecin, Poland. ${ }^{2}$ Department of General Pathology, Pomeranian Medical University, Rybacka 1, 70-204 Szczecin, Poland. ${ }^{3}$ Jerzy Haber Institute of Catalysis and Surface Chemistry Polish Academy of Sciences, Niezapominajek 8, 30-239 Cracow, Poland. ${ }^{4}$ Department of Biochemistry, Pomeranian Medical University, Rybacka 1, $70-204$ Szczecin, Poland.

\section{Competing interests}

The authors declare no competing interests.

\section{Consent for publication}

We agree for publication.

\section{Data availability}

The data required to reproduce these findings are availability for any research. 
Acknowledgements

We thank the National Centre for Research and Development for financial support this study (grant number Strategmed1/234261/2NCBR/2014).

\section{Ethics approval and consent to participate}

Ethical approval and consent were not needed in this study.

\section{References}

1. Patra, J. K.; Das, G.; Fraceto, L. F.; Campos, E. V. R.; Rodriguez-Torres, M. D. P.; Acosta-Torres, L. S.; Diaz-Torres, L. A.; Grillo, R.; Swamy, M. K.; Sharma, S.; Habtemariam, S.; Shin, H.-S., Nano based drug delivery systems: recent developments and future prospects. Journal of nanobiotechnology 2018,16 (1), 71-71.

2. Wang, E. C.; Wang, A. Z., Nanoparticles and their applications in cell and molecular biology. Integrative Biology 2013,6 (1), 9-26.

3. Bahadar, H.; Maqbool, F.; Niaz, K.; Abdollahi, M., Toxicity of Nanoparticles and an Overview of Current Experimental Models. Iranian biomedical journal 2016,20 (1), 1-11.

4. Dreher, K. L., Health and environmental impact of nanotechnology: toxicological assessment of manufactured nanoparticles. Toxicol Sci 2004,77 (1), 3-5.

5. Suk, J. S.; Xu, Q.; Kim, N.; Hanes, J.; Ensign, L. M., PEGylation as a strategy for improving nanoparticle-based drug and gene delivery. Advanced Drug Delivery Reviews 2016,99, 28-51.

6. Spicer, C. D.; Jumeaux, C.; Gupta, B.; Stevens, M. M., Peptide and protein nanoparticle conjugates: versatile platforms for biomedical applications. Chemical Society Reviews 2018,47(10), 3574-3620.

7. Yu, M.; Wu, J.; Shi, J.; Farokhzad, O. C., Nanotechnology for protein delivery: Overview and perspectives. J Control Release 2016,240, 24-37.

8. Allen, S. J.; Watson, J. J.; Shoemark, D. K.; Barua, N. U.; Patel, N. K., GDNF, NGF and BDNF as therapeutic options for neurodegeneration. Pharmacol Ther 2013,138 (2), 155-75.

9. Upadhyay, R. K., Drug delivery systems, CNS protection, and the blood brain barrier. BioMed research international 2014,2014, 869269-869269.

10. Gustafson, H. H.; Holt-Casper, D.; Grainger, D. W.; Ghandehari, H., Nanoparticle uptake: The phagocyte problem. Nano Today 2015,10 (4), 487-510.

11. Zhu, Y.; Liu, C.; Pang, Z., Dendrimer-Based Drug Delivery Systems for Brain Targeting. Biomolecules 2019,9 (12), 790.

12. Eichman, J. D.; Bielinska, A. U.; Kukowska-Latallo, J. F.; Baker, J. R., The use of PAMAM dendrimers in the efficient transfer of genetic material into cells. Pharmaceutical Science \& Technology Today 2000,3 (7), 232-245. 
13. Florendo, M.; Figacz, A.; Srinageshwar, B.; Sharma, A.; Swanson, D.; Dunbar, G. L.; Rossignol, J., Use of Polyamidoamine Dendrimers in Brain Diseases. Molecules (Basel, Switzerland) 2018,23 (9), 2238.

14. Menjoge, A. R.; Kannan, R. M.; Tomalia, D. A., Dendrimer-based drug and imaging conjugates: design considerations for nanomedical applications. Drug Discov Today 2010,15 (5-6), 171-85.

15. Luong, D.; Kesharwani, P.; Deshmukh, R.; Mohd Amin, M. C. I.; Gupta, U.; Greish, K.; Iyer, A. K., PEGylated PAMAM dendrimers: Enhancing efficacy and mitigating toxicity for effective anticancer drug and gene delivery. Acta Biomaterialia 2016,43, 14-29.

16. Behzadi, S.; Serpooshan, V.; Tao, W.; Hamaly, M. A.; Alkawareek, M. Y.; Dreaden, E. C.; Brown, D.; Alkilany, A. M.; Farokhzad, O. C.; Mahmoudi, M., Cellular uptake of nanoparticles: journey inside the cell. Chemical Society Reviews 2017,46 (14), 4218-4244.

17. Fröhlich, E., The role of surface charge in cellular uptake and cytotoxicity of medical nanoparticles. International journal of nanomedicine 2012,7, 5577-5591.

18. Fox, L. J.; Richardson, R. M.; Briscoe, W. H., PAMAM dendrimer - cell membrane interactions. Advances in Colloid and Interface Science 2018,257, 1-18.

19. Majoros, I. J.; Williams, C. R.; Becker, A. C.; Baker, J. R., Surface Interaction and Behavior of Poly(amidoamine) Dendrimers: Deformability and Lipid Bilayer Disruption. Journal of Computational and Theoretical Nanoscience 2009,6 (7), 1430-1436.

20. Xiao, K.; Li, Y.; Luo, J.; Lee, J. S.; Xiao, W.; Gonik, A. M.; Agarwal, R. G.; Lam, K. S., The effect of surface charge on in vivo biodistribution of PEG-oligocholic acid based micellar nanoparticles. Biomaterials 2011,32 (13), 3435-3446.

21. Nguyen, V. H.; Lee, B.-J., Protein corona: a new approach for nanomedicine design. International journal of nanomedicine 2017,12, 3137-3151.

22. Zhao, J.; Stenzel, M. H., Entry of nanoparticles into cells: the importance of nanoparticle properties. Polymer Chemistry 2018,9 (3), 259-272.

23. Lopes, F. M.; Schroder, R.; da Frota, M. L., Jr.; Zanotto-Filho, A.; Muller, C. B.; Pires, A. S.; Meurer, R. T.; Colpo, G. D.; Gelain, D. P.; Kapczinski, F.; Moreira, J. C.; Fernandes Mda, C.; Klamt, F., Comparison between proliferative and neuron-like $\mathrm{SH}-\mathrm{SY} 5 \mathrm{Y}$ cells as an in vitro model for Parkinson disease studies. Brain Res 2010,1337, 85-94.

24. Lehmensiek, V.; Tan, E.-M.; Liebau, S.; Lenk, T.; Zettlmeisl, H.; Schwarz, J.; Storch, A., Dopamine transporter-mediated cytotoxicity of 6-hydroxydopamine in vitro depends on expression of mutant alpha-synucleins related to Parkinson's disease. Neurochemistry international 2006,48 (5), 329-340.

25. Xicoy, H.; Wieringa, B.; Martens, G. J. M., The SH-SY5Y cell line in Parkinson's disease research: a systematic review. Molecular Neurodegeneration 2017,12 (1), 10.

26. Xie, H. R.; Hu, L. S.; Li, G. Y., SH-SY5Y human neuroblastoma cell line: in vitro cell model of dopaminergic neurons in Parkinson's disease. Chin Med J (Engl) 2010,123 (8), 1086-92.

27. J, T.; SP, K.; TP, M.; DJ, N.; MJ, R., Increased plasma malondialdehyde levels in glomerular disease as determined by a fully validated HPLC method. Nephrology, dialysis, transplantation : official 
publication of the European Dialysis and Transplant Association - European Renal Association 1999,14 (4).

28. Zbigniew, A.; Anna, B.-S.; Paulina Zeliszewska and Monika, W., Mechanisms of Fibrinogen Adsorption at Solid Substrates. Current Topics in Medicinal Chemistry 2014,14 (6), 702-729.

29. Wasilewska, M.; Adamczyk, Z., Fibrinogen Adsorption on Mica Studied by AFM and in Situ Streaming Potential Measurements. Langmuir 2011,27 (2), 686-696.

30. Malmsten, M., Ellipsometry Studies of Protein Layers Adsorbed at Hydrophobic Surfaces. Journal of Colloid and Interface Science 1994, 166 (2), 333-342.

31. Ortega-Vinuesa, J. L.; Tengvall, P.; Lundström, I. I., Aggregation of HSA, IgG, and Fibrinogen on Methylated Silicon Surfaces. J Colloid Interface Sci 1998,207 (2), 228-239.

32. Toscano, A.; Santore, M. M., Fibrinogen Adsorption on Three Silica-Based Surfaces: Conformation and Kinetics. Langmuir 2006,22 (6), 2588-2597.

33. S, K.; MM, S., Non-specific adhesion on biomaterial surfaces driven by small amounts of protein adsorption. Colloids and surfaces. B, Biointerfaces 2009,73 (2).

34. Dąbkowska, M.; Adamczak, M.; Barbasz, J.; Cieśla, M.; Machaliński, B., Adsorption/Desorption Transition of Recombinant Human Neurotrophin 4: Physicochemical Characterization. Langmuir 2017,33 (38), 9548-9557.

35. Y, J.; JM, F.; CD, P.; N, V.; Y, Z.; K, B.; S, Q.; DS, M.; X, Y.; WA, B.; AV, K., Nanoformulation of Brain-Derived Neurotrophic Factor with Target Receptor-Triggered-Release in the Central Nervous System. Advanced functional materials 2018,28 (6).

36. Dąbkowska, M.; Łuczkowska, K.; Rogińska, D.; Sobuś, A.; Wasilewska, M.; Ulańczyk, Z.; Machaliński, B., Novel design of (PEG-ylated)PAMAM-based nanoparticles for sustained delivery of BDNF to neurotoxin-injured differentiated neuroblastoma cells. J Nanobiotechnology 2020,18 (1), 120.

37. V, M.-M.; JP, P.; I, A.-D.; R, R.; S, V.; V, R.; J, F.; F, C.; L, V.; FD, G.-N.; C, O., Effect of Terminal Groups of Dendrimers in the Complexation with Antisense Oligonucleotides and Cell Uptake. Nanoscale research letters 2016,11 (1).

38. A, V. S.; D, L.; S, D.-C.; C, D.-G., Protein-based polyelectrolyte multilayers. Advances in colloid and interface science $\mathbf{2 0 2 0 , 2 8 0 .}$

39. W, W.; W, X.; J, W.; X, S.; H, X.; X, Y., The decrease of PAMAM dendrimer-induced cytotoxicity by PEGylation via attenuation of oxidative stress. Nanotechnology 2009,20 (10).

40. N, M.; H, F.; L, S.; S, B.; M, Z.; T, B., Molecular Modeling to Study Dendrimers for Biomedical Applications. Molecules (Basel, Switzerland) 2014,19(12).

41. B, W.; Y, S.; TP, D.; PC, K.; Y, W.; F, D., Understanding Effects of PAMAM Dendrimer Size and Surface Chemistry on Serum Protein Binding with Discrete Molecular Dynamics Simulations. ACS sustainable chemistry \& engineering 2018,6 (9).

42. G, Y.; N, K.; EM, N., Impact of Dendrimer Terminal Group Chemistry on Blockage of the Anthrax Toxin Channel: A Single Molecule Study. Toxins 2016,8 (11). 
43. Dąbkowska, M.; Adamczyk, Z., Human Serum Albumin Monolayers on Mica: Electrokinetic Characteristics. Langmuir 2012,28 (44), 15663-15673.

44. Dąbkowska, M.; Adamczyk, Z., Mechanism of immonoglobulin G adsorption on mica-AFM and electrokinetic studies. Colloids and Surfaces B: Biointerfaces 2014,118, 57-64.

45. Bratek-Skicki, A.; Żeliszewska, P.; Adamczyk, Z.; Cieśla, M., Human Fibrinogen Monolayers on Latex Particles: Role of lonic Strength. Langmuir 2013,29 (11), 3700-3710.

46. Dąbkowska, M.; Adamczyk, Z.; Cieśla, M.; Adamczak, M.; Bober, J., Lysozyme Monolayers at Polymer Microparticles: Electrokinetic Characteristics and Modeling. The Journal of Physical Chemistry $C$ 2018,122 (31), 17846-17855.

47. Serra, J.; Puig, J.; Martín, A.; Galisteo, F.; Gálvez, M.; Hidalgo-Alvarez, R., On the adsorption of IgG onto polystyrene particles: electrophoretic mobility and critical coagulation concentration. Colloid and Polymer Science 1992,270 (6), 574-583.

48. Dabkowska, M.; Adamczak, M.; Barbasz, J.; Ciesla, M.; Machalinski, B., Adsorption/Desorption Transition of Recombinant Human Neurotrophin 4: Physicochemical Characterization. Langmuir 2017,33 (38), 9548-9557.

49. T, L.; J, W.; JJ, V.-D.; K, L.; M, K.; SK, W.; M, Ö.; ML, M., Adsorption of Proteins on Colloidal Lignin Particles for Advanced Biomaterials. Biomacromolecules 2017,18 (9).

50. S, D. L.; F, C.; P, S.; MH, S.; SC, S., Binding and Release between Polymeric Carrier and Protein Drug: pH-Mediated Interplay of Coulomb Forces, Hydrogen Bonding, van der Waals Interactions, and Entropy. Biomacromolecules 2017,18(11).

51. F, C.; G, M.; LJ, T., Investigating possible changes in protein structure during dendrimer-protein binding. Organic \& biomolecular chemistry 2010,8 (22).

52. Giri, J.; Diallo, M. S.; Simpson, A. J.; Liu, Y.; Goddard, W. A.; Kumar, R.; Woods, G. C., Interactions of Poly(amidoamine) Dendrimers with Human Serum Albumin: Binding Constants and Mechanisms. ACS Nano 2011,5 (5), 3456-3468.

53. Lamy, C. M.; Sallin, O.; Loussert, C.; Chatton, J. Y., Sodium sensing in neurons with a dendrimer-based nanoprobe. ACS Nano 2012,6 (2), 1176-87.

54. B, W.; RS, N.; AR, M.; B, B.; R, B.; H, D.; R, R.; S, K.; RM, K., Inhibition of bacterial growth and intramniotic infection in a guinea pig model of chorioamnionitis using PAMAM dendrimers. International journal of pharmaceutics 2010,395 (1-2).

55. L, A.; M, S.; A, A.; F, B., Dendrimer internalization and intracellular trafficking in living cells. Molecular pharmaceutics 2010,7 (3).

56. Li, Y.; Pei, Y.; Zhang, X.; Gu, Z.; Zhou, Z.; Yuan, W.; Zhou, J.; Zhu, J.; Gao, X., PEGylated PLGA nanoparticles as protein carriers: synthesis, preparation and biodistribution in rats. $J$ Control Release 2001,71 (2), 203-11.

57. Kouchakzadeh, H.; Shojaosadati, S. A.; Maghsoudi, A.; Vasheghani Farahani, E., Optimization of PEGylation conditions for BSA nanoparticles using response surface methodology. AAPS PharmSciTech 2010,11 (3), 1206-11. 
58. Pelaz, B.; del Pino, P.; Maffre, P.; Hartmann, R.; Gallego, M.; Rivera-Fernández, S.; de la Fuente, J. M.; Nienhaus, G. U.; Parak, W. J., Surface Functionalization of Nanoparticles with Polyethylene Glycol: Effects on Protein Adsorption and Cellular Uptake. ACS Nano 2015,9 (7), 6996-7008.

59. Janaszewska, A.; Lazniewska, J.; Trzepiński, P.; Marcinkowska, M.; Klajnert-Maculewicz, B., Cytotoxicity of Dendrimers. Biomolecules 2019,9 (8), 330.

60. Naha, P. C.; Byrne, H. J., Generation of intracellular reactive oxygen species and genotoxicity effect to exposure of nanosized polyamidoamine (PAMAM) dendrimers in PLHC-1 cells in vitro. Aquatic Toxicology 2013,132-133, 61-72.

61. Oberdörster, G.; Oberdörster, E.; Oberdörster, J., Nanotoxicology: an emerging discipline evolving from studies of ultrafine particles. Environmental health perspectives 2005,113 (7), 823-839.

62. Su, L.-J.; Zhang, J.-H.; Gomez, H.; Murugan, R.; Hong, X.; Xu, D.; Jiang, F.; Peng, Z.-Y., Reactive Oxygen Species-Induced Lipid Peroxidation in Apoptosis, Autophagy, and Ferroptosis. Oxidative medicine and cellular longevity $\mathbf{2 0 1 9 , 2 0 1 9 , 5 0 8 0 8 4 3 - 5 0 8 0 8 4 3 .}$

63. Mukherjee, S. P.; Lyng, F. M.; Garcia, A.; Davoren, M.; Byrne, H. J., Mechanistic studies of in vitro cytotoxicity of poly(amidoamine) dendrimers in mammalian cells. Toxicol Appl Pharmacol 2010,248 (3), 259-68.

64. Ayala, A.; Muñoz, M. F.; Argüelles, S., Lipid peroxidation: production, metabolism, and signaling mechanisms of malondialdehyde and 4-hydroxy-2-nonenal. Oxidative medicine and cellular longevity 2014,2014, 360438-360438.

65. Somani, S.; Laskar, P.; Altwaijry, N.; Kewcharoenvong, P.; Irving, C.; Robb, G.; Pickard, B. S.; Dufès, C., PEGylation of polypropylenimine dendrimers: effects on cytotoxicity, DNA condensation, gene delivery and expression in cancer cells. Scientific reports 2018,8 (1), 9410-9410.

66. Lopez, A. I.; Reins, R. Y.; McDermott, A. M.; Trautner, B. W.; Cai, C., Antibacterial activity and cytotoxicity of PEGylated poly(amidoamine) dendrimers. Mol Biosyst 2009,5 (10), 1148-56.

67. Guo, C.; Sun, L.; Chen, X.; Zhang, D., Oxidative stress, mitochondrial damage and neurodegenerative diseases. Neural regeneration research 2013,8 (21), 2003-2014.

68. Nyitrai, G.; Héja, L.; Jablonkai, I.; Pál, I.; Visy, J.; Kardos, J., Polyamidoamine dendrimer impairs mitochondrial oxidation in brain tissue. Journal of nanobiotechnology 2013,11, 9-9.

69. Labieniec, M.; Gabryelak, T., Preliminary biological evaluation of poli(amidoamine) (PAMAM) dendrimer G3.5 on selected parameters of rat liver mitochondria. Mitochondrion 2008,8 (4), 305-312.

\section{Figures}



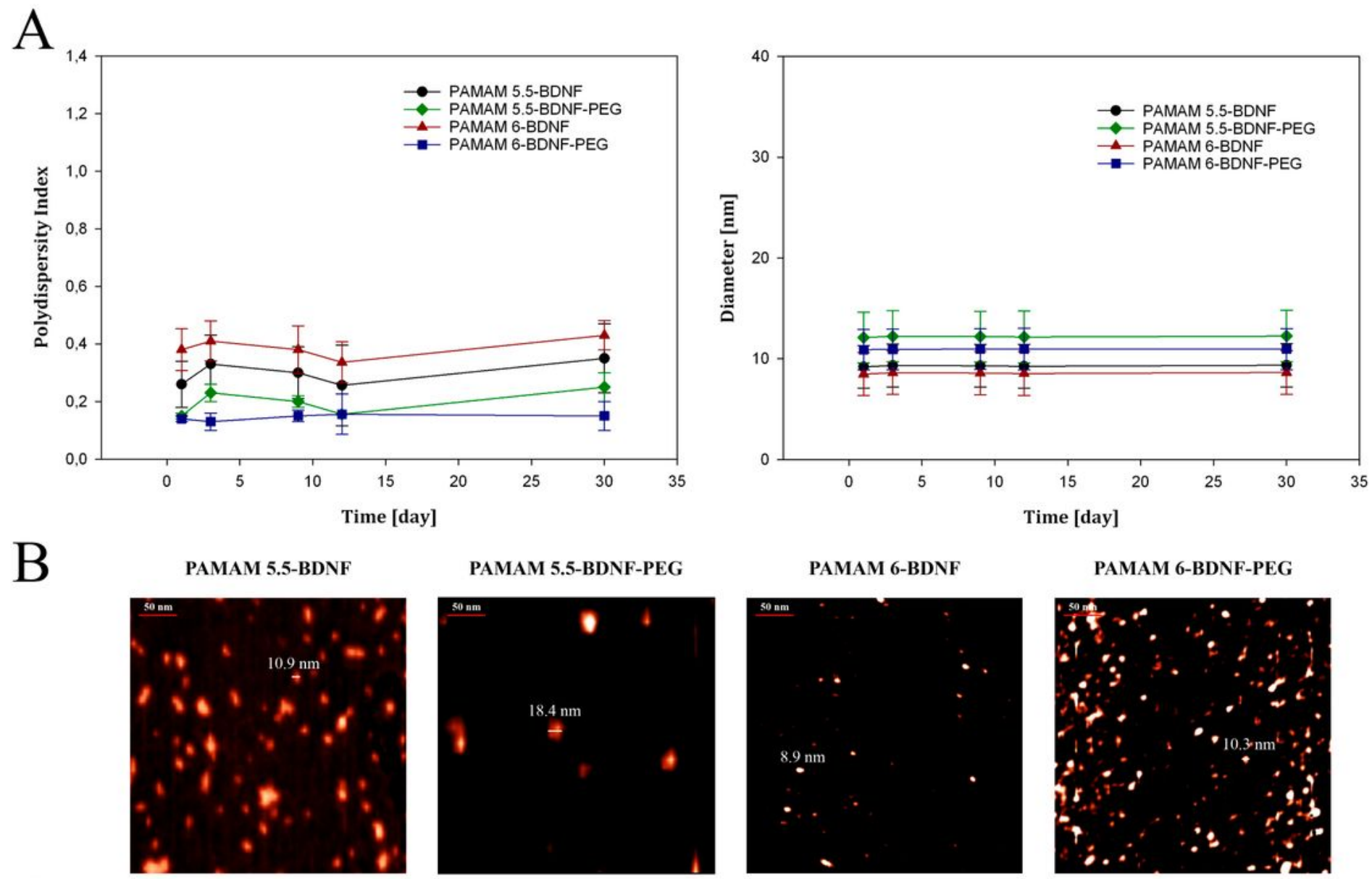

PAMAM 5.5-BDNF-PEG
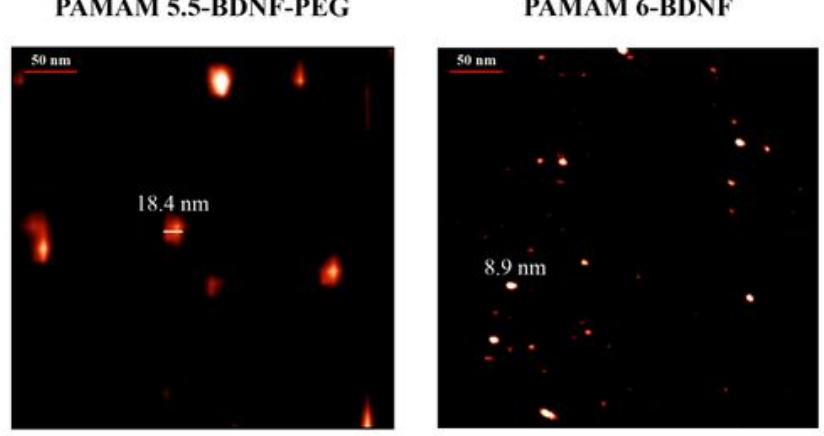

PAMAM 6-BDNF-PEG
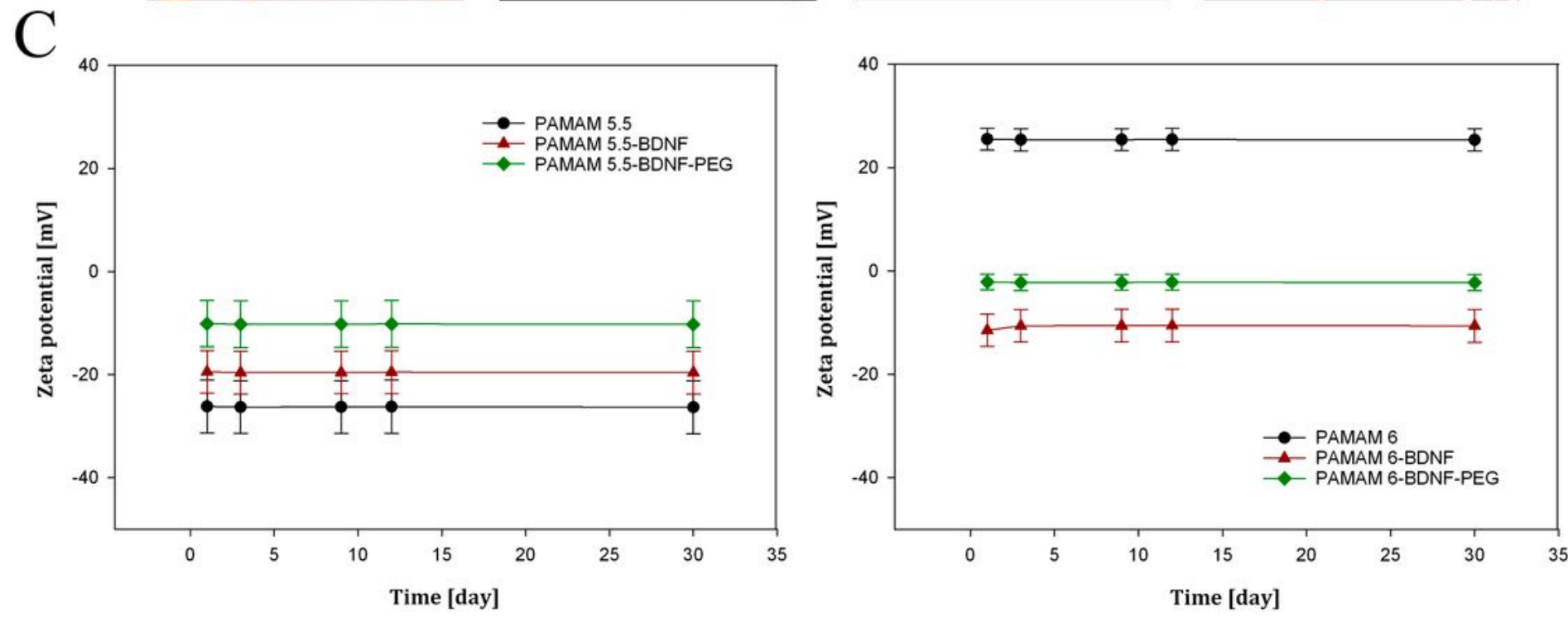

\section{Figure 1}

Physicochemical characterization of BDNF-PAMAM as well as PEG-ylated BDNF-PAMAM nanoparticles with positively and negatively charged dendrimers core. Serum stability of nanoparticles studied using DLS. Particle size distribution (A) and hydrodynamic diameter (B) of BDNF-PAMAM5.5, BDNF-PAMAM5.5PEG, BDNF-PAMAM6, BDNF-PAMAM6-PEG nanoparticles, measured against PAMAM dendrimers core nanoparticles (without BDNF). All samples were incubated in PBS with 10\% FBS over 30 days. All 
experiments were performed in triplicates and error bars represent mean \pm standard deviation (SD) (A and C). The dependence of the zeta potential of positively charged PAMAM 6 or negatively charged PAMAM5.5 dendrimers core on the initial BDNF concentration of $0.1 \mathrm{mgL}-1$ in the suspension in $\mathrm{PBS}, \mathrm{pH}$ 7.4, 0.15 M ionic strength (C). Representative AFM "high" diagrams (B) of BDNF-PAMAM5.5, BDNFPAMAM5.5-PEG, BDNF-PAMAM6, BDNF-PAMAM6-PEG nanoparticles adsorbed at mica surface at $0.15 \mathrm{M}$ $\mathrm{pH} 7.4$ in PBS at a scan area of $0.5 \times 0.5 \mu \mathrm{m}$ and structure of PAMAM-based nanoparticles after crosssection.

A
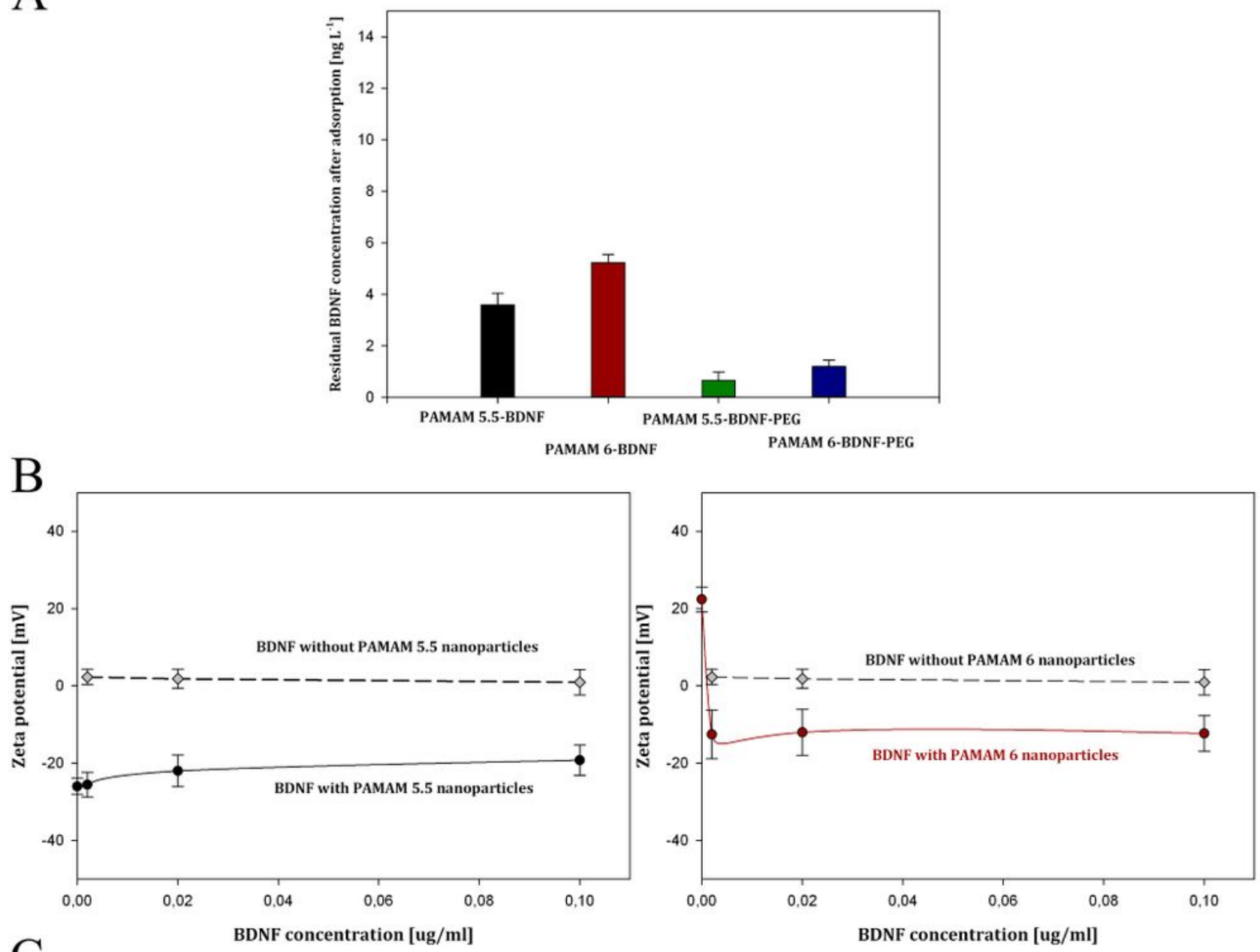

$\mathrm{C}$

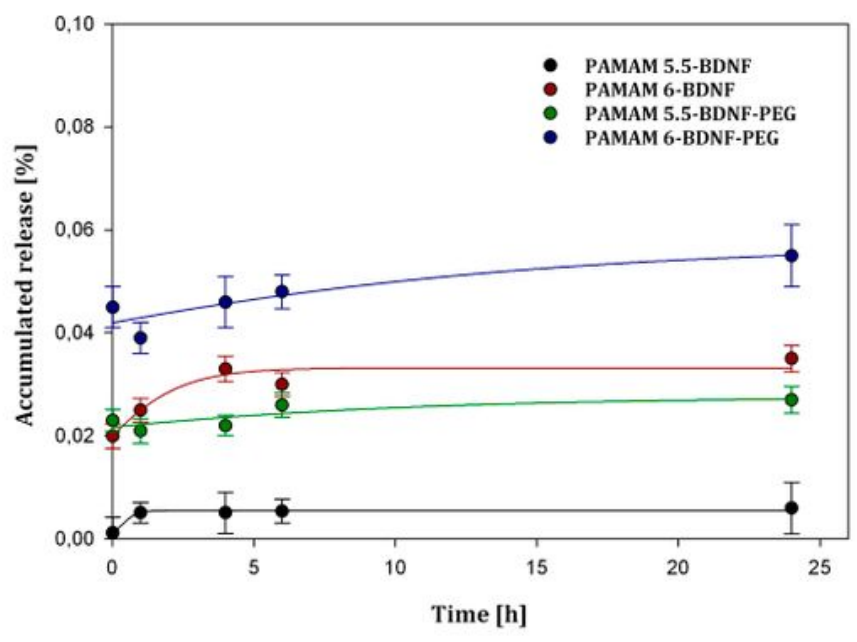




\section{Figure 2}

Loading and releasing of BDNF from BDNF-PAMAM as well as PEG-ylated BDNF-PAMAM nanoparticles with positively and negatively charged dendrimers core. Encapsulation efficiency (A): Dependence of residual BDNF concentration after adsorption step at PAMAM nanoparticles on initial protein concentration after 1h's adsorption. Encapsulation efficiency (B): The dependence of the zeta potential of positively charged PAMAM 6 or negatively PAMAM5.5 dendrimers core on the initial BDNF concentration in the suspension $0.1 \mathrm{mgL}-1$ in PBS after mixing pH 7.4, 0.15 M ionic strength. (C) BDNF release profile from BDNF-PAMAM and PEG-ylated BDNF-PAMAM nanoparticles with various charge dendrimer core in PBS. 


\section{Cell viability [\%]}

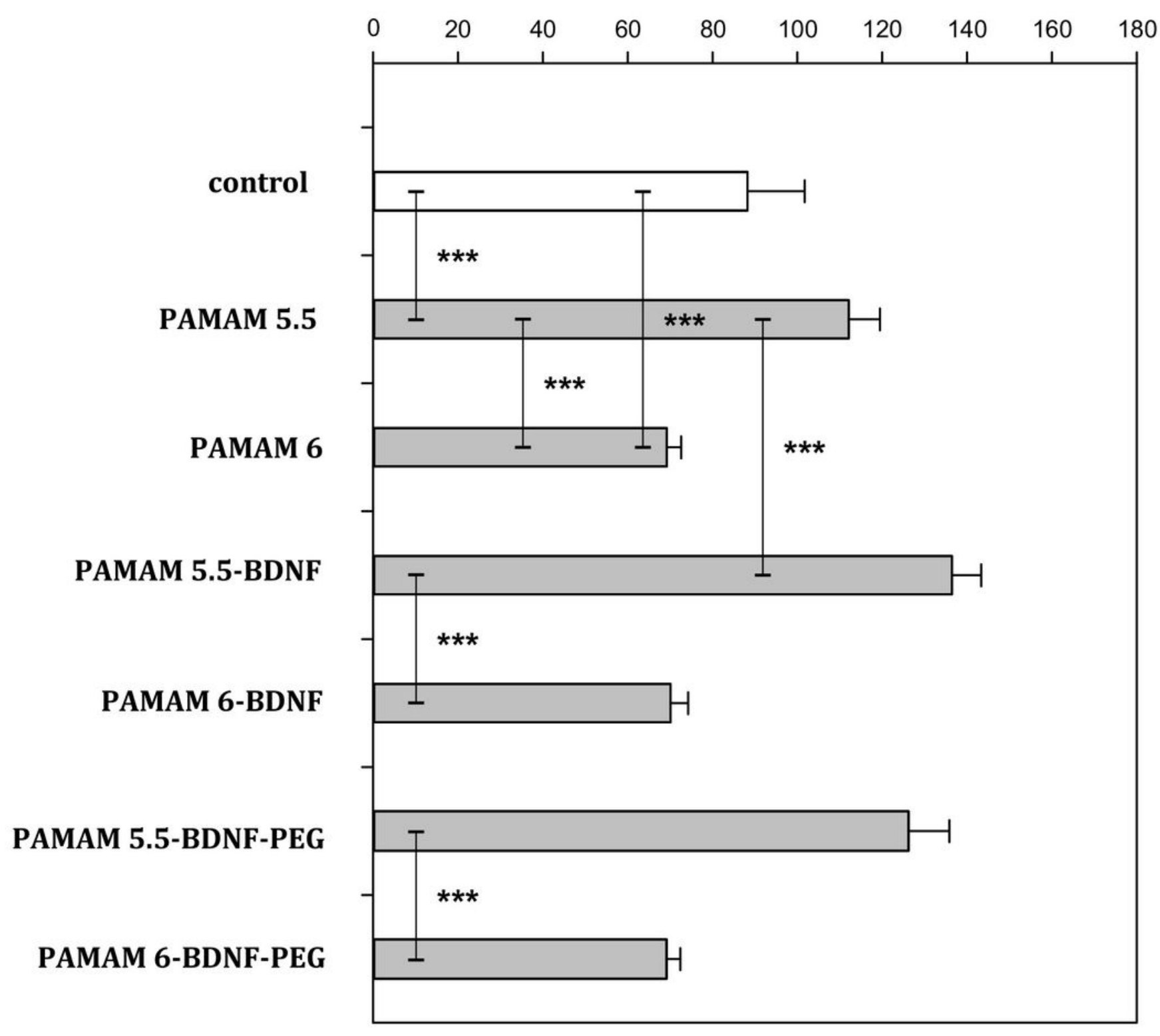

Figure 3

Cell viability of differentiated human neuroblastoma cell line SH-SY5Y exposed to $20 \mu \mathrm{mol} / \mathrm{L} 6-\mathrm{OHDA}$ neurotoxin and treated with differently charged PAMAM cores, PAMAM- and PEGylated PAMAM-based nanoparticles. The control (100\% viability) are cells treated with $20 \mu \mathrm{mol} / \mathrm{L} 6-\mathrm{OHDA}$ only. The data represent means +/- SD for 30 experiments. 
A In vitro BDNF concentration in cell supernatants [ng $\mathrm{L}^{-1}$ ]

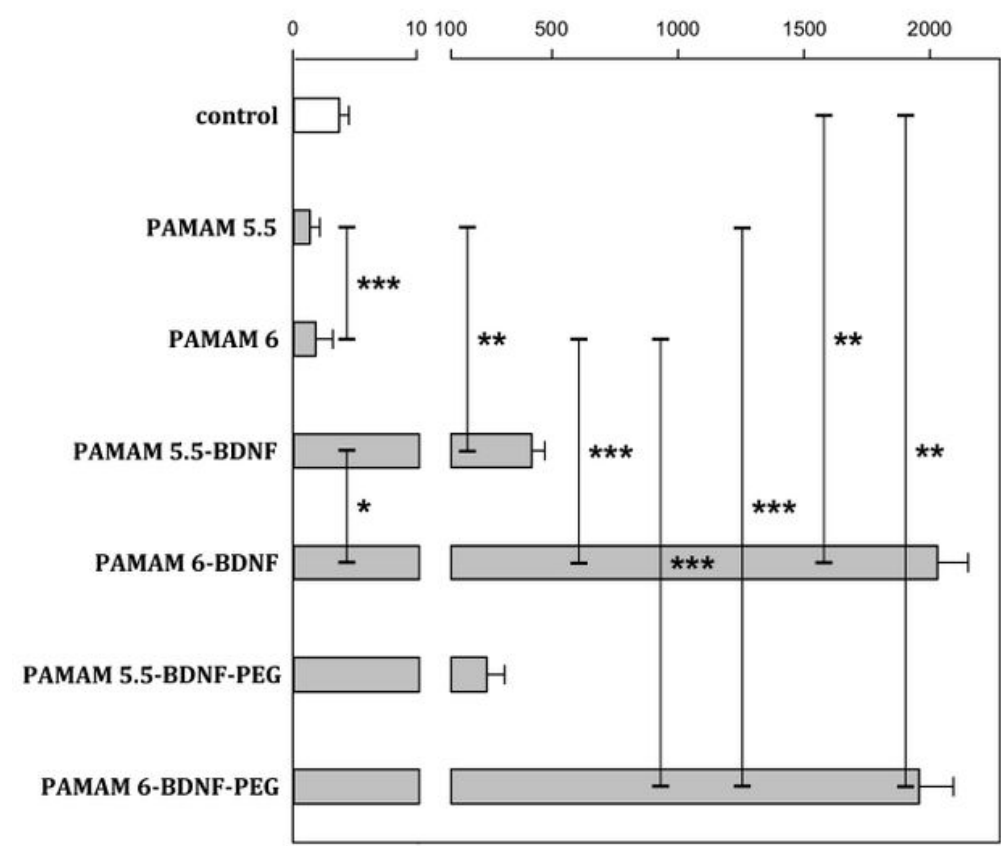

B

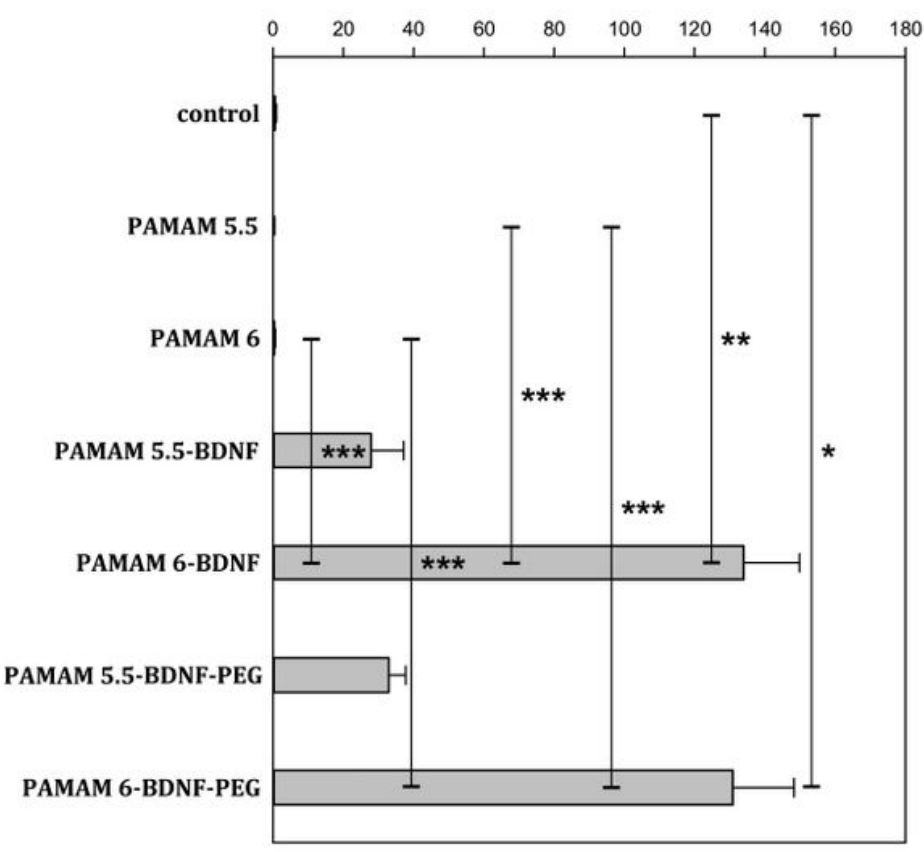

\section{Figure 4}

Desorption characteristic of BDNF from BDNF-PAMAM and PEG-ylated BDNF-PAMAM nanoparticles with differently charged dendrimer core in cell culture lysates and supernatant under carriers loading of protein concentrations equal to $0.1 \mathrm{mgL}-1$. BDNF detection by ELISA over 24h in cells incubated with PAMAM 5.5 (no BDNF), PAMAM 5.5- BDNF, PAMAM 5.5- BDNF-PEG, PAMAM 6 (no BDNF), PAMAM6 - BDNF-, PAMAM 6- BDNF-PEG The data represent means +/- SD for five experiments. 

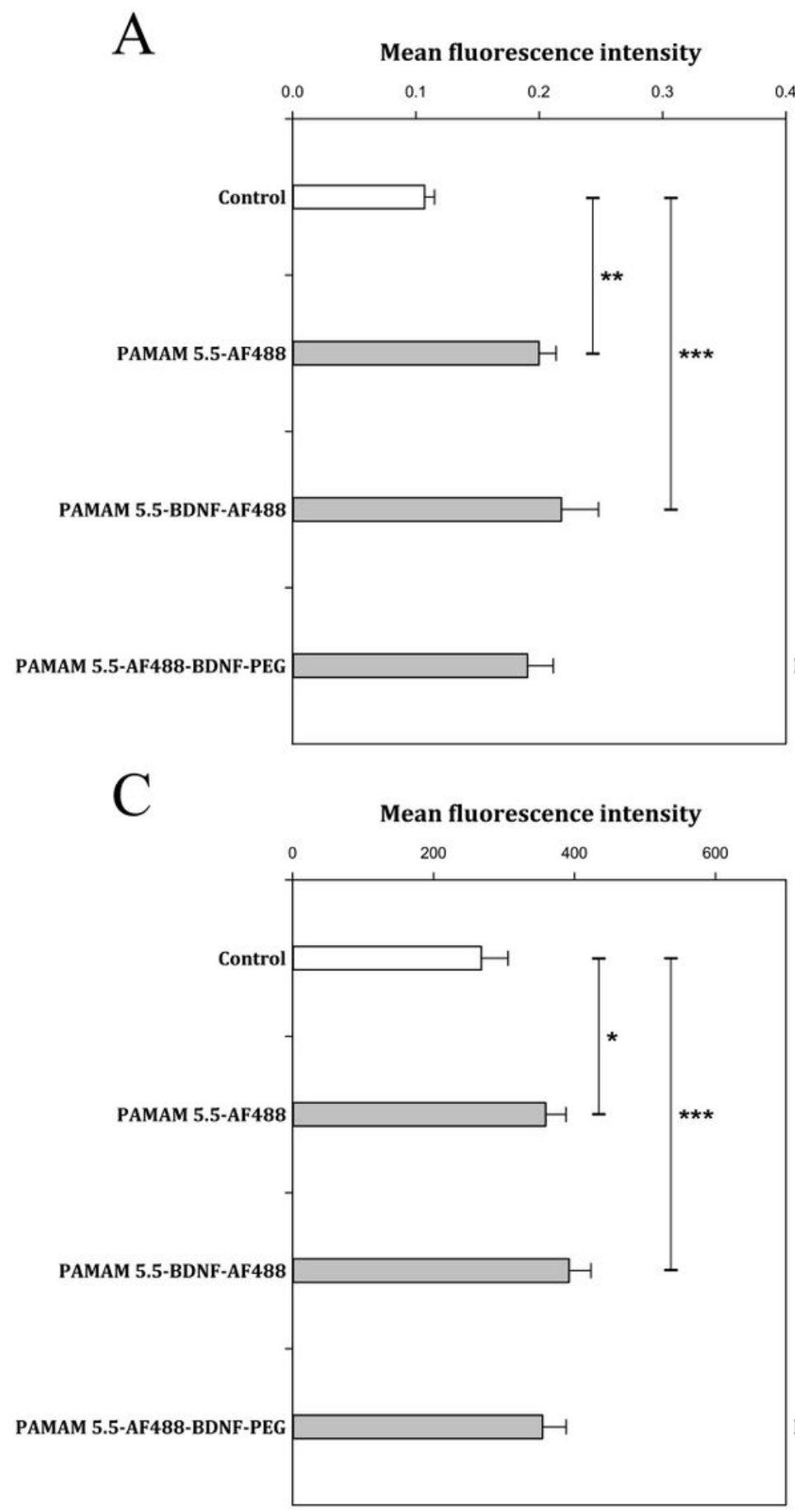

B

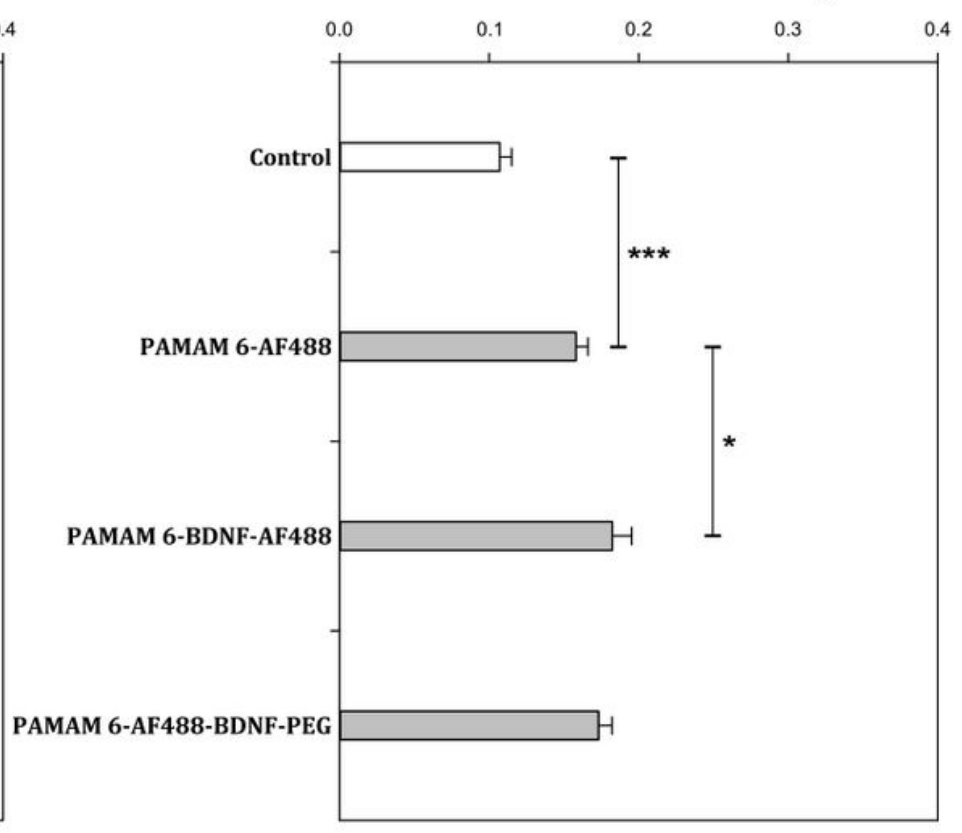

$\mathrm{D}$

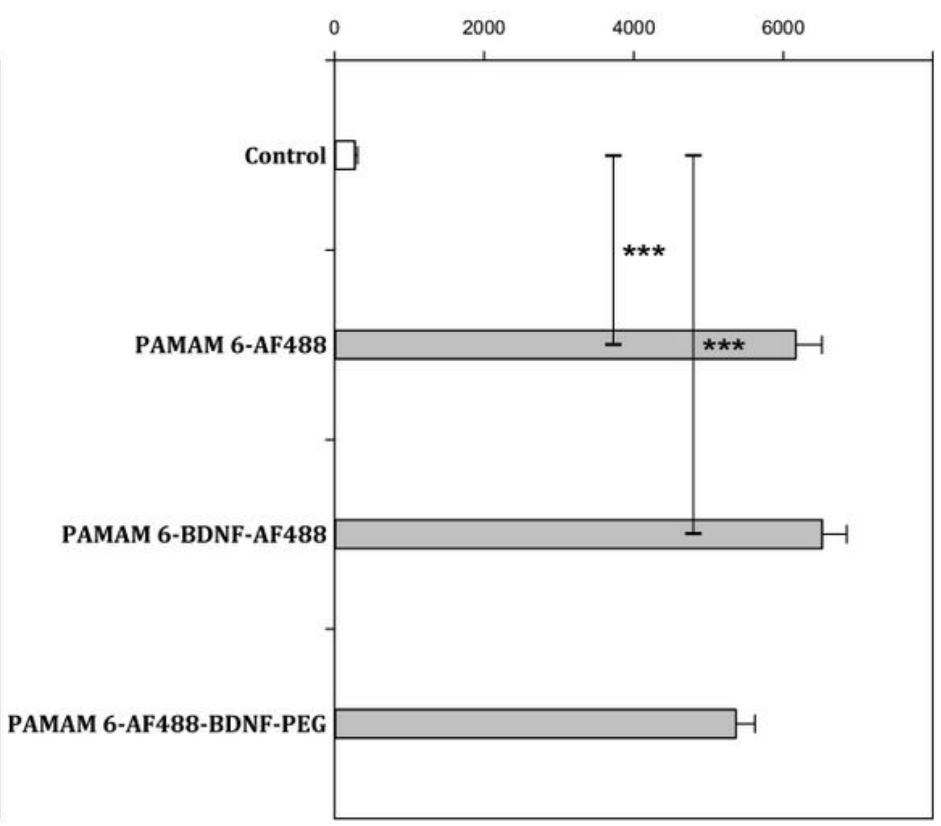

\section{Figure 5}

Immunofluorescence assessment of dendrimers-based nanoparticles localization in differentiated human neuroblastoma cell line SH-SY5Y upon treatment for $24 \mathrm{~h}$. Data is presented as the mean +/- SD $(n=12)$. Data distribution was tested using Shapiro-Wilk test. To compare two analysed datasets the unpaired ttest was used. The analysis of variances between different time-points was performed using one-way ANOVA. * $-p<0.05, * \star-p<0.01, * \star \star-p<0.001$. 

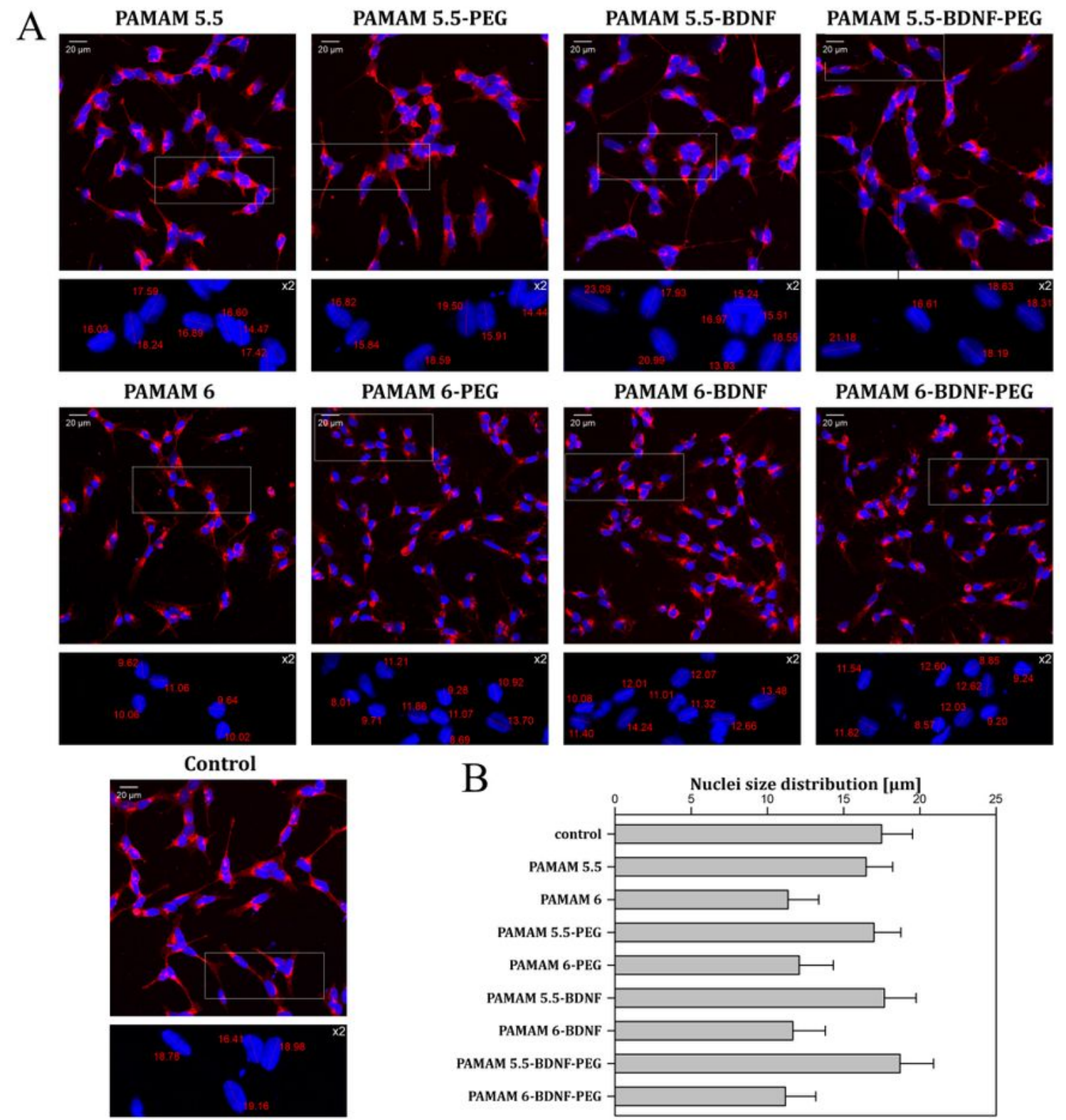

C

\begin{tabular}{|c|c|c|c|c|c|c|c|c|c|}
\hline & Control & PAMAM 5.5 & PAMAM 6 & $\begin{array}{l}\text { PAMAM 5.5- } \\
\text { PEG }\end{array}$ & $\begin{array}{l}\text { PAMAM 6- } \\
\text { PEG }\end{array}$ & $\begin{array}{l}\text { PAMAM 5.5- } \\
\text { BDNF }\end{array}$ & $\begin{array}{c}\text { PAMAM 6- } \\
\text { BDNF }\end{array}$ & $\begin{array}{l}\text { PAMAM 5.5- } \\
\text { BDNF-PEG }\end{array}$ & $\begin{array}{l}\text { PAMAM 6- } \\
\text { BDNF-PEG }\end{array}$ \\
\hline Control & & & $\cdots$ & & $* * *$ & & $\cdots$ & $*$ & $\cdots$ \\
\hline PAMAM 5.5 & & & $\cdots$ & & $\cdots$ & $\ddot{*}$ & $\cdots$ & $\cdots *$ & *.* \\
\hline PAMAM 6 & $\cdots$ & $\cdots$ & & $* *$ & & $\cdots$ & & $* *$ & \\
\hline PAMAM 5.5-PEG & & & *** & & $* * *$ & & $* * *$ & $* * *$ & $* * *$ \\
\hline PAMAM 6-PEG & $\cdots$ & $\cdots$ & & $* *$ & & ... & & $* * *$ & \\
\hline PAMAM 5.5-BDNF & & $*$ & $\cdots$ & & *** & & $\cdots$ & & $\cdots *$ \\
\hline PAMAM 6-BDNF & $\cdots$ & $\cdots$ & & *** & & $\cdots$ & & $\cdots$ & \\
\hline PAMAM 5.5-BDNF-PEG & $\cdot$ & $\cdots$ & $\cdots$ & $* *$ & *** & & $\cdots$ & & $\cdots *$ \\
\hline PAMAM 6-BDNF-PEG & $* * *$ & $* * *$ & & $* * *$ & & $* * *$ & & $* * *$ & \\
\hline
\end{tabular}

\section{Figure 6}

Analysis of morphological alterations in RA-differentiated 6-OHDA treated SH-SY5Y cells incubated with PAMAM 5.5, PAMAM 5.5-PEG, PAMAM 5.5-BDNF $(0.1 \mu \mathrm{g} / \mathrm{ml})$, PAMAM 5.5-BDNF $(0.1 \mu \mathrm{g} / \mathrm{ml})$-PEG, PAMAM 6, PAMAM 6-PEG, PAMAM 6-BDNF $(0.1 \mu \mathrm{g} / \mathrm{ml})$ and PAMAM 6-BDNF $(0.1 \mu \mathrm{g} / \mathrm{ml})$-PEG. A: confocal images of WGA stained SH-SY5Y cells (red - surface glycoproteins; blue - nuclei), magnification x200. A selected region has been enlarged twice and presented below each of the main pictures with marked cell 
nuclei measurements (presented in $\mu \mathrm{m}$ ). B: chart representing nuclei size distribution in all assessed study groups. Values are presented as mean \pm SD. C: table summarizing the statistical analysis results. Calculations were performed using Kruskal-Wallis test. * $p \leq 0.05, * * p \leq 0.01, * \star * p \leq 0.001$.
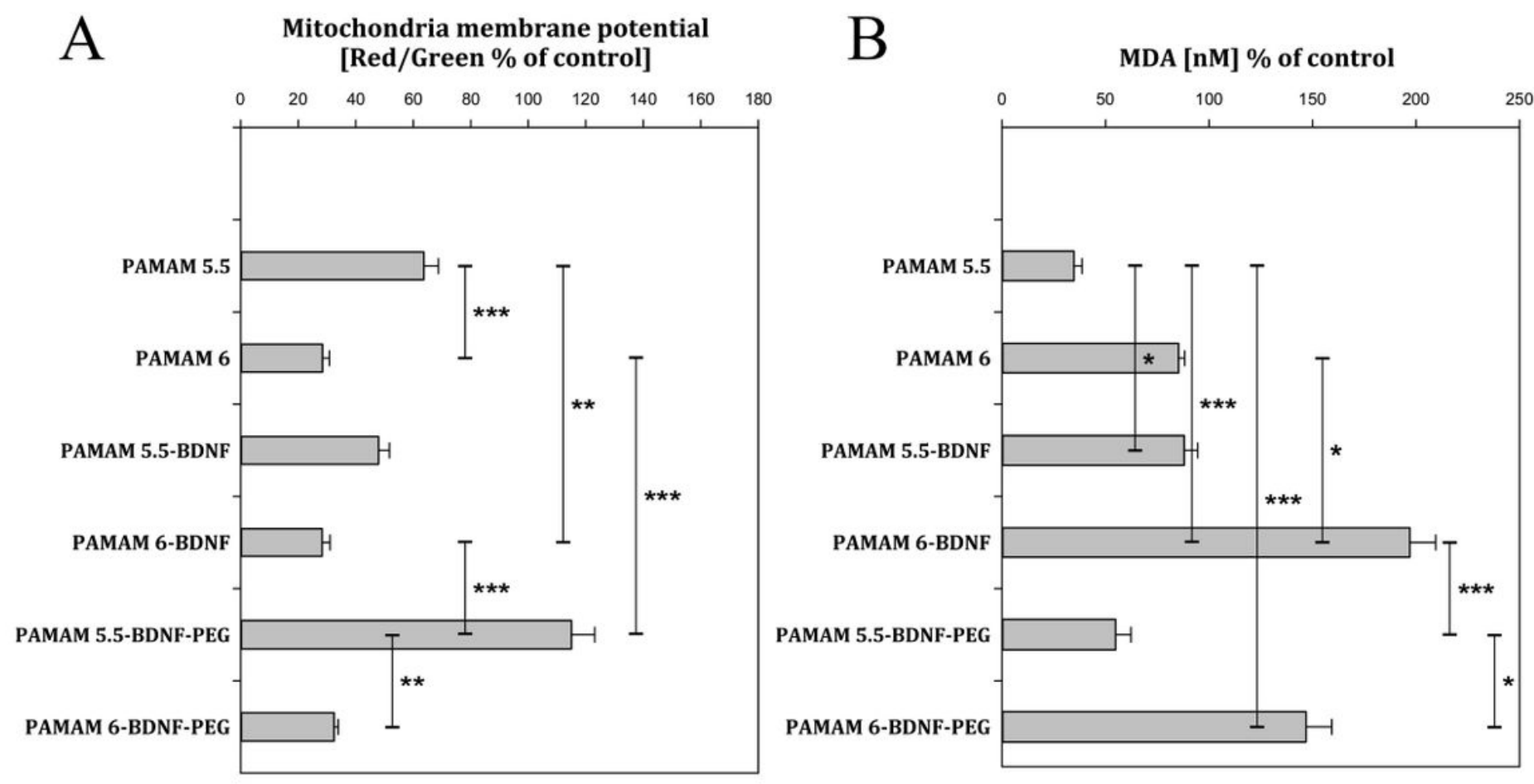

\section{Figure 7}

Assessment of dendrimers-based nanoparticles mitochondrial membrane potential (part A) and MDA (part B) in neuron-like differentiated human neuroblastoma cell line SH-SY5Y upon treatment for 24h. Data is presented as the mean +/-SD $(n=12)$. Data distribution was tested using Shapiro-Wilk test. To compare two analyzed datasets the unpaired t-test was used. The analysis of variances between different time-points was performed using one-way ANOVA. * $-p<0.05,{ }^{*}-p<0.01,{ }^{* \star}-p<0.001$.

\section{Supplementary Files}

This is a list of supplementary files associated with this preprint. Click to download.

- MSchargeSupportingInfo31.03.2021.docx

- SupplementaryMaterials.pdf

- Grapicalabstract.pdf 